\title{
Macroeconomic Stabilization Policies IN THE EMU: SPILLOVERS, ASYMMETRIES, AND INSTITUTIONS
}

\author{
GIOVANNI Di BARTOLOMEO \\ JACOB ENGWERDA \\ JOSEPH PLASMANS \\ BAS VAN AARLE \\ TOMASZ MICHALAK
}

CESIFO WORKING PAPER NO. 1376

CATEGORY 6: MoNETARY Policy AND INTERNATIONAL FinANCE JANUARY 2005

\footnotetext{
An electronic version of the paper may be downloaded

- from the SSRN website: www.SSRN.com

- from the CESifo website: www.CESifo.de
} 


\title{
MACROECONOMIC STABILIZATION POLICIES IN THE EMU: SPILLOVERS, ASYMMETRIES, AND INSTITUTIONS
}

\begin{abstract}
This paper studies the institutional design of the coordination of macroeconomic stabilization policies within a monetary union in the framework of linear quadratic differential games. A central role in the analysis plays the partitioned game approach of the endogenous coalition formation literature. The specific policy recommendations in the EMU context depend on the particular characteristics of the shocks and the economic structure. In the case of a common shock, fiscal coordination or full policy coordination is desirable. When asymmetric shocks are considered, fiscal coordination improves the performance but full policy coordination doesn't produce further gains in policymakers' welfare.
\end{abstract}

JEL Code: C70, E17, E58, E61, E63.

Keywords: macroeconomic stabilization, EMU, coalition formation, linear quadratic differential games.

Giovanni Di Bartolomeo

University of Rome, Faculty of Economics

Via del Castro Laurenziano 9

00161 Rome, Italy

giovanni.dibartolomeo@uniromal.it
Jacob Engwerda

Tilburg University, Dept. of Economics

P.O. Box 90153

5000 LE Tilburg, The Netherlands

j.c.engwerda@uvt.nl

Joseph Plasmans

University of Antwerp, Dept. of Economics

Prinsstraat 13

2000 Antwerp, Belgium

joseph.plasmans@ua.ac.be

Bas van Aarle

Catholic University of Leuven

Deberiotstraat, 34

3000 Leuven, Belgium

bas.vanaarle@econ.kuleuven.ac.be

\author{
Tomasz Michalak \\ University of Antwerp \\ Prinsstraat 13 \\ 2000 Antwerp, Belgium \\ Tomasz.michalak@ua.ac.be
}

We are grateful to conference and seminar participants at Coordination Failures Conference (University Paris X-Nanterre, June 2004), EcoMod 2002 (Brussels), the AFSE Conference on 'Growth, Convergence and European Integration' (Lille, 2003) and the University of Antwerp for useful comments on the first preliminary version of this paper. Giovanni Di Bartolomeo acknowledges the financial support from the University of Rome 'La Sapienza' (MURST 2000) and the University of Antwerp (Special Research Fund), and Bas van Aarle and Tomasz Michalak acknowledge the financial support from the FWO (Fonds voor Wetenschappelijk Onderzoek Vlaanderen). 


\section{Introduction}

The main institutional change of the EMU is clearly the constitution of a common central bank (European Central Bank - ECB). Moreover, fiscal policies are now regulated according to the Broad Economic Policy Guidelines (BEPGs) established by the European Commission (EC) in 2000 and the decisions taken within the ECOFIN Council of (Economics and Finance) Ministers (for the whole EU) and the Eurogroup (for the EMU). ${ }^{1}$ For example, the fiscal policy of the EU Member States is monitored within the framework of the BEPGs by the EC with recommendations, warnings, and judgements. An example is the ECOFIN Council recommendation to Ireland on the 12th of February 2001, addressing the inconsistency between the Irish budget for 2001 and the BEPGs. Other cases are the recommendations with early warnings by the EC for Germany and Portugal on the 11th of February 2002 and more recently - on the 21st of January 2003 - for France. However, the institutions and the procedures for economic policy coordination are far from being completely established, and, therefore, several matters are still under discussion. Having this context in mind, this paper studies the institutional design of the coordination of macroeconomic stabilization policies within the EMU and its consequences on macroeconomic outcomes and policies.

Fiscal policy coordination in a monetary union is directly linked to the sizes and signs of the spillovers and externalities resulting from national fiscal policies. Fiscal spillovers are crucial since they ultimately determine whether coordination should lead to a more expansionary or a more restrictive fiscal stance in the member states. For example, if governments perceive negative spillovers in a static game, they would interpret a noncooperative ("beggar-thy-neighbour") policy in response to bad economic shocks as too expansionary and would agree on a more restrictive stance in all countries. By contrast, if governments perceive positive spillovers, coordination should eliminate free-riding behaviour of individual countries and promote more expansionary policy in response to bad economic shocks. In a dynamic setting the situation is more complicated as the size, persistence and signs of the spillovers may markedly change over time.

The EMU is clearly a highly integrated economic area with a large number of interactions between the participating countries. However, empirical estimations of spillovers in such a context are not (yet) available ${ }^{2}$ and the theoretical literature does not provide a clear-cut answer about the sign of fiscal policy spillovers. The traditional argument in favour of international policy coordination is based on direct positive demand spillovers. By contrast, more recent, micro-founded models of the EMU tend to conclude in favour of negative fiscal spillovers by emphasizing the adverse terms-of-trade effects of balancedbudget foreign fiscal expansion on the domestic economy. Furthermore, the possibility of accumulating public debts might add other sources of negative spillovers through the common nominal interest rate.

\footnotetext{
${ }^{1}$ The Eurogroup, however, is not officially institutionalized, but is an informal meeting of the Ministers of Finance of the EMU-member states.

${ }^{2}$ A very preliminary attempt to estimate cross-country spillovers within the EMU is provided by Monteforte and Siviero (2003). Moreover, Monfort et al. (2002) try to empirically disentangle common shocks and spillover effects in a multi-country setting.
} 
In the EMU a central role is played by the coordination of the fiscal policies among the national governments ${ }^{3}$ and, moreover, their coordination with the monetary policy of the ECB. ${ }^{4}$ In general, two kinds of coordination can be distinguished (Beetsma et al. (2001)): institutional (or ex-ante) coordination, and policy (or ex-post) coordination.

The ex-ante coordination is related to the institutional framework, the coordination procedures, and the design of policy rules, whereas ex-post coordination takes place from the current state of affairs and concerns the actual policy decisions. More in particular, ex-ante coordination operates through formal binding agreements recognized by the policymakers as international obligations (e.g. the Maastricht Treaty and the Stability and Growth Pact (SGP)). By contrast, ex-post coordination has an informal character, and refers to discretionary and $a d$ hoc informal agreements stipulated among the countries. ${ }^{5}$ The two kinds of coordination are strictly interconnected. In fact, e.g., the SGP might strongly reduce the room for discretionary coordination of the national fiscal policies. Similarly, discretionary agreements among the countries might depend on the design of the European institutions concerning fiscal cooperation as e.g. the ECOFIN Council.

The institutional framework (ex-ante coordination) is introduced by considering different rules, procedures and information shared among policymakers, which taken together characterize the negotiations among policymakers in determining cooperation agreements. Different institutional settings may have different effects on the implementation of cooperative policies. In fact, some institutional setups may not be able to promote cooperation, even when cooperative policies increase the welfare of policymakers because of free-riding behaviour.

Ex-post coordination will be studied in a dynamic framework to emphasize the dynamic character of both direct and indirect spillovers arising from the behaviour of national fiscal policies in an integrated area as the EMU. The direct spillovers from fiscal policies result from the effect of domestic output on foreign output via the export channel. The indirect spillovers result from the effects of fiscal policies on the dynamics of inflation rates, intra-EMU competitiveness, and interest rates.

Our paper extends the literature in two respects.

(a) From the methodological point of view, this paper extends Di Bartolomeo et al. (2004) by considering a more general shock structure - based on inflation instead of competitiveness - in the model dynamics. Moreover, more general inflation dynam-

\footnotetext{
${ }^{3}$ Inflation bias, which may arise in the setting of fiscal policy, is likely to be stronger in a multi-country monetary union with nationally-set fiscal policies than in the case of EMU-wide set fiscal policies. It is important, therefore, to design institutions for commitment and coordination of fiscal policies in order to mitigate such biases (CESifo (2002, Chapter 3)).

${ }^{4}$ Also some global interdependencies, primarily with the USA, can be important. See Neck et al. (2002) for the study of policy coordination in a global context.

${ }^{5}$ As it is pointed out by Beetsma et al. (2001), we can think of the Eurogroup, in which the Finance Ministers of the EMU-area discuss fiscal policies in an informal way, as a forum of ex-post co-ordination. Furthermore, also the ECOFIN Council, notwithstanding its more formal nature, is characterized by largely discretionary decisions and can, therefore, be interpreted as a formal institution where not only formal but also informal agreements take place.
} 
ics are considered: the effects of foreign inflation rates are included, as suggested by the recent open economies' literature. ${ }^{6}$

(b) In this paper we also extend the current literature on the institutional design (exante coordination) of the EMU by taking account of a dynamic framework. After solving the $n$-country model analytically according to the linear-quadratic methodology, we expose the main features of our model by numerical simulations based on structural form parameters. In the numerical simulations, we will analyze the consequences of ex-ante and ex-post policy coordination under different assumptions on the sign and size of the fiscal spillovers, and on the asymmetries among the EMU Member States. The different forms of asymmetry that will be investigated are: countries having asymmetric structural model parameters (structural asymmetry), policymakers having different preferences (preference asymmetry), and, finally, shocks that asymmetrically hit countries (shock asymmetry).

The paper is organized as follows. Section 2 provides a small dynamic macroeconomic model of the EMU economy and the dynamic stabilization problem the fiscal policymakers and the common monetary authority are facing. Section 3 discusses in detail the institutional aspects of policy coordination in the EMU context and how these aspects are incorporated into our analysis. Section 4 analyzes the consequences of $e x-$ post and ex-ante policy coordination in a dynamic framework by studying numerical simulations of various examples.

\section{The basic economic framework}

In this section we describe our basic framework. We consider a model where $n$ countries $(\bar{N}:=\{1,2 \ldots n\})$ participate in a monetary union. Each economy is described by an aggregate demand/IS curve and an aggregate supply curve (derived from a Phillips relationship). All the variables are in logarithms, except for the interest rate which is in perunages, and denote deviations from their long-run equilibrium that has been normalized to zero, for simplicity. A dot above a variable denotes its time derivative.

Equations (1) are the IS curves which represent the aggregate demand (AD) in each of the EMU countries as a function of competitiveness in intra-EMU trade, the domestic real interest rate, the foreign real output gaps, and the domestic real fiscal deficit. Hence, the aggregate demand satisfies:

$$
x_{i}(t)=-\gamma_{i}\left[i_{E}(t)-\dot{p}_{i}(t)\right]+\eta_{i} f_{i}(t)+\sum_{j \in \bar{N} / i} \rho_{i j} x_{j}(t)+\sum_{j \in \bar{N} / i} \delta_{i j}\left[p_{j}(t)-p_{i}(t)\right]
$$

in which $x$ denotes the real output gap (defined as real output relative to potential real output $\left.^{7}\right), f$ the real fiscal deficit, $p$ the price level, and $i_{E}$ the common nominal interest

\footnotetext{
${ }^{6}$ Evidence of foreign inflation effects on the Phillips curve is provided by DiNardo and Moore (1999). See also Razin and Yuen (2001) and Plasmans et al. (2004).

${ }^{7}$ In this paper, it is assumed that the equilibrium real output gap has been normalized to zero for convenience (as for all the other variables).
} 
rate in the EMU area. The (expected) real interest rate is defined as the difference between the nominal common interest rate and the inflation in a country. Although the nominal interest rate is the same for the whole Euro area, real interest rates diverge among countries if inflation rates are different.

Equations (2) are open economy Phillips curves, which describe the aggregate supply $(\mathrm{AS})$ in each of the EMU countries:

$$
\dot{p}_{i}(t)=\zeta_{i} x_{i}(t)+\sum_{j \in \bar{N} / i} \varsigma_{i j} \dot{p}_{j}(t), \quad p_{i}(0)=p_{i 0}
$$

Aggregate supply is assumed to be determined by a Phillips curve implied by the existence of some (nominal) rigidities in the goods (and/or labour) markets giving rise to a short-run trade-off between inflation and output. In this Phillips relationship the inflation rates of the other countries play a role since foreign inflation is passed through via domestic imports of foreign intermediate goods and also via the possibility that domestic wage claims rise, given the presence of a real wage wedge. In accordance with our short-run stabilization focus, the effectiveness of fiscal policy is limited to its transitory impact on the output gap through the induced stimulus of the aggregate demand. The initial values of domestic prices represent (initial) supply/cost shocks that hit the economy at time zero.

Within the above economic framework, we assume that the fiscal authorities control their fiscal policy instrument such as to minimize the following quadratic loss function, ${ }^{8}$ which features domestic inflation, real output gap, and real fiscal deficit, with respect to the control variable $f_{i}$ :

$$
J_{i}\left(t_{0}\right)=\frac{1}{2} \int_{t_{0}}^{\infty}\left\{\alpha_{i} \dot{p}_{i}^{2}(t)+\beta_{i} x_{i}^{2}(t)+\chi_{i} f_{i}^{2}(t)\right\} e^{-\theta\left(t-t_{0}\right)} d t
$$

in which $\theta$ denotes the rate of time preference and $\alpha_{i}, \beta_{i}$, and $\chi_{i}$ represent preference weights that are attached to the stabilization of inflation, output, and fiscal discipline, respectively (in general, $\beta_{i}>\alpha_{i}$ ). In particular, parameter $\chi_{i}$ is an indicator for the stringency of the rules imposed by the SGP. A higher value of $\chi_{i}$ in this interpretation means that the SGP is more strictly interpreted and high deficits bear high costs.

We choose the EMU wide nominal interest rate as the ECB's monetary policy instrument and add an interest rate smoothing objective in the ECB's cost function, to express the ECB's caution in setting monetary policy. Consequently, we assume that the ECB is confronted with the following optimization problem:

$$
\min _{i_{u}} J_{E C B}\left(t_{0}\right)=\min _{i_{u}} \frac{1}{2} \int_{t_{0}}^{\infty}\left\{\alpha_{E C B} \dot{p}_{u}^{2}(t)+\beta_{E C B} x_{u}^{2}(t)+\chi_{E C B} i_{u}^{2}(t)\right\} e^{-\theta\left(t-t_{0}\right)} d t
$$

\footnotetext{
${ }^{8}$ Note that the quadratic form of the loss function implies that policymakers are equally concerned about inflation and deflation and about a negative output gap vs. a positive one. This may not always be realistic; however, such an assumption is necessary to keep the analysis more tractable.
} 
where $\dot{p}_{u} \equiv \sum_{i=1}^{n} \sigma_{i} \dot{p}_{i}$ is aggregate inflation; $x_{u} \equiv \sum_{i=1}^{n} \sigma_{i} x_{i}$ is loglinearized aggregate output $;{ }^{9} \alpha_{E C B}$ and $\beta_{E C B}$ indicate the relative preferences of the ECB concerning inflation and output of the EMU as a whole. Parameter $\sigma_{i}$ indicates the relative weight of country $i$ in the euro zone $\left(\sum_{i=1}^{n} \sigma_{i}=1\right)$. The minimization of this loss function w.r.t. $i_{u}(t)$ is consistent with the derivation of a standard monetary policy rule (see e.g. Clarida et al. (1999)), since it results in a linear function in its arguments.

The structural form model (1)-(2) can be transformed into the following reduced form model: ${ }^{10}$

$$
\left[\begin{array}{c}
x(t) \\
\dot{p}(t)
\end{array}\right]=\left[\begin{array}{ccc}
D & E & M \\
A & B & N
\end{array}\right]\left[\begin{array}{c}
p(t) \\
f(t) \\
i_{u}(t)
\end{array}\right]
$$

where $x(t)$ is a country-ordered vector of output gaps, $\dot{p}(t)$ is a country-ordered vector of inflation rates, $p(t)$ and $f(t)$ are the price level and fiscal deficit vectors, respectively. ${ }^{11}$ The partitioned matrix $L:=\left[\begin{array}{ccc}D & E & M \\ A & B & N\end{array}\right]$ indicates the elasticities of the real output gap and inflation rate with respect to price levels and control instruments. The upper part of matrix $L \in \mathbb{R}^{2 n \times(2 n+1)}$ indicates the instantaneous elasticities of the real output gaps. The lower part of this matrix indicates the elasticities of the inflation dynamics of the model. The matrix $L$ is crucial in the analysis of the externalities. More in detail, the matrix $E \in \mathbb{R}^{n \times n}$ describes the effects of the domestic fiscal policy on the domestic real output gaps (main diagonal elements) and those of the foreign fiscal policies on the domestic real output gaps (off-diagonal elements); the latter elasticities are called fiscal externalities. Similarly, the matrix $B \in \mathbb{R}^{n \times n}$ describes the effects of the fiscal policy variables on the inflation rates. Matrices $D \in \mathbb{R}^{n \times n}$ and $A \in \mathbb{R}^{n \times n}$ indicate the effects of domestic and foreign price levels on the domestic real output gaps and inflation rates, respectively. Vectors $M \in \mathbb{R}^{n}$ and $N \in \mathbb{R}^{n}$ are the semi-elasticities of the real output gaps and inflation rates w.r.t. to the common nominal interest rate.

\section{Institutional setup and cooperative mechanisms}

The current policy framework of the EMU presents a strong asymmetry between the management of fiscal and monetary policies. The common monetary policy is deter-

\footnotetext{
${ }^{9}$ The following two-country example illustrates the procedure of loglinearization. Assuming that the real output $X_{i}(t)$ is in the neighbourhood of the steady state output $\bar{X}_{i}$, the following approximation holds: $\frac{X_{i}(t)}{\bar{X}_{i}(t)} \simeq 1+x_{i}(t)$. The aggregate output equation $X_{u}(t) \equiv X_{1}(t)+X_{2}(t)$ can be rewritten as $1=\frac{X_{1}(t)}{X_{u}(t)}+\frac{X_{2}(t)}{X_{u}(t)}$ and by rules of loglinearization transformed into $1 \simeq \frac{\bar{X}_{1}}{X_{u}}\left(1+x_{1}(t)-x_{u}(t)\right)+$ $\frac{\bar{X}_{2}}{\bar{X}_{u}}\left(1+x_{2}(t)-x_{u}(t)\right)$. Simplifying we obtain: $x_{u}(t) \equiv \log \frac{X_{u}(t)}{X_{u}}=\sigma_{1} x_{1}(t)+\sigma_{2} x_{2}(t)$ where $\sigma_{1} \equiv \frac{\bar{X}_{1}}{X_{u}}$ and $\sigma_{2} \equiv \frac{\bar{X}_{2}}{\bar{X}_{u}}$ are relative weights of the countries' output. Hence, it follows that $x_{u}(t)$ is the aggregate output gap.

${ }^{10}$ For the derivation of the reduced form of the model refer to the Appendix (see footnote 7).

${ }^{11}$ Clearly, the dimension of all these vectors is $n$.
} 
mined by a supranational policymaker (the ECB) with a statutory primary objective, achieving and maintaining price stability in the EMU area. By contrast, fiscal policies remain in the hands of the EMU Member States, with no objective specified by the Treaty but constrained by the SGP requirements. This decentralized management of the fiscal policies raises several issues on the need of ex-post coordination among member governments and the eventual alternative mechanisms that can guarantee ex-ante coordination. ${ }^{12}$

The ex-ante coordination among fiscal policymakers can be implemented according to positive or negative mechanisms. In the EU positive fiscal coordination is barely used with the exception of the BEPGs, which, however, are formally non-binding. By contrast, the SGP, which is a negative coordination mechanism punishing countries running excessive public deficits, constitutes the core of the EMU architecture. The SGP allows the ECB to "play on the safe side" by putting a strong limit to the discretional power of the national governments in setting their independent fiscal policies (Onorante (2002)).

In the ongoing debate, it is argued that increased coordination should include 1) a greater sharing of information among the member states; 2) a greater positive coordination; and 3) a progressive reduction of the importance of negative (rule based) coordination. ${ }^{13}$

In this paper the institutional design issue and ex-ante positive coordination are introduced by assuming that policymakers, who face a stabilization problem in the EMU, play a two-stage game. In the first stage (the coalition game) they decide non-cooperatively whether or not to coordinate their fiscal policies after that common or country-specific shocks have been observed. In the second stage (the stabilization game) they play a noncooperative dynamic game, where those policymakers, who have signed the agreement, play as a single player sharing a common loss function. The rules of the first-stage game determine the institutional setup (ex-ante coordination), whereas the second stage of the game describes ex-post coordination. According to the rules determined in the institutional coordination negotiations, different coalition structures may emerge when ex-post coordination is considered. Negative coordination is determined by the magnitude of the costs associated with the fiscal stance prescribed by the SGP.

Unfortunately, game theory is far from having achieved a well defined non-cooperative theory of coalition formation. There are, however, a few different stability concepts that can be used to model endogenous coalition formation in solving the coalition game (first stage). In fact, according to Ecchia and Mariotti (1998), different equilibrium concepts can be seen as different institutional contexts where policymakers act. Hence, different equilibria can be used to derive indications about optimal institutional design of the EMU. Such an approach can be of a particular interest in the current European debate on the institutional design of the EMU (see Hughes Hallett and Viegi (2003)).

\footnotetext{
${ }^{12}$ Although several studies have investigated the effects of (needs for) fiscal and/or monetary coordination, only a few have challenged the issue of the mechanism of co-ordination by comparing alternative schemes (see e.g. van Aarle et al. (2002a) and Onorante (2002)).

${ }^{13}$ These guidelines are however not fully agreed. For example, Uhlig (2002) claims that the SGP needs strengthening rather than weakening (so he calls for an increase of negative co-ordination).
} 
We consider four possible candidate equilibrium concepts for the first stage of the game: Coalitional Nash Equilibrium (CNE), Farsighted Coalitional Equilibrium (FCE), Sequential Negotiation Equilibrium (SNE) and Sequential Negotiation Game Equilibrium (SNGE).

The first one is based on the standard Nash equilibrium concept and was introduced into the coalition literature by the seminal studies of d'Aspremont et al. (1983). ${ }^{14}$ $\mathrm{CNE}$ is the result of a one-shot game where agents simultaneously face the problem of accepting or rejecting a proposal that consists in sharing their loss function and cooperatively setting their instruments. After that all agents' decisions are taken, the CNE is formed. ${ }^{15}$

Regarding FCE, we consider the possibility of reaching final decisions about the coordination on the basis of a sequentially repeated negotiation process that ends when there are no further opportunities of gains for the players. FCE is based on the idea of indirect domination, which implies farsightedness (see e.g. Chwe (1994) and Mariotti (1998)). The indirect domination concept captures the idea that each agent (or coalition of agents), who deviates from a given coalition structure, has anticipated further deviations of other agents. Specifically, this equilibrium implies that member states and the ECB are able to forecast the reactions of (the) other policymakers to their actions. We solve the FCE-game assuming that no player can refuse the proposal to play cooperatively (open-membership assumption) and no group deviations are possible. Differently from the other stability concepts, a deviation is possible even if it does not improve (immediately) the utility of the deviating agent. In fact, an agent can strategically deviate to induce the other players to take actions that in the end will lead her to a stable coalition structure where she gets a higher payoff. An algorithm that helps to find FCEs is reported in the Appendix.

The last two coalition formation mechanisms, SNGE and SNE, are based on the assumption that decisions about fiscal policies are determined by the national governments and that coordination is built on the basis of a hierarchical sequential negotiation process. ${ }^{16}$ These mechanisms emphasize the possible role played by single countries in the negotiation for achieving a coordination agreement, e.g. that with the temporary EU President Country. In this case, the EU Presidency determines a list of proponents (list of order) among the ministers of the member countries, and then each minister, according to this list of order, proposes a coalition to a group of countries. Countries that accept a proposal exit from the game. The final result of such a negotiation scheme under the assumption of perfect information is an SNGE. In the Appendix we describe an algorithm for the computation of a unique SNGE. This mechanism has, however,

\footnotetext{
${ }^{14}$ Several variants of this concept are surveyed in Carraro and Siniscalco (1998).

${ }^{15}$ See Carraro (1998) or van Aarle et al (2002b) for a more detailed definition of the CNE equilibrium.

${ }^{16}$ Inspired by Bloch (1996) and Ray and Vohra (1999) we define an SNGE as a hierarchical multi-stage negotiation process (the algorithm is presented in the Appendix, see footnote 7). The main modification of Bloch (1996) is that every coalition can be proposed only once. In the SNE, differently from SNGE, we assume that players instead of acting strategically have bounded rationality. When they decide to propose, accept or reject a coalition they look at the immediate consequence of their choice, not taking the further choices of other players into account.
} 
several drawbacks. The most important of them is that the outcome can depend on the list of order. Hence, various questions concerning institutions and procedures arise: e.g. who determines that list since the list of order can be chosen strategically as to determine a possible coalition? Availability of perfect information can rarely be a case in a real-world monetary union. The SNE-mechanism is a model for an institutionalized decision-making process that might be used in the situation when players know only own losses in different coalition structures and when they are risk-averse. We assume that in such a situation all the players agree to use certain standardized procedures of negotiations that can be to some extent compared to the SNGE-rules. Formally, the difference is that the SNE-equilibrium is found not via backward induction, like in the case of the SNGE, but using a procedure based on the well known minimax concept.

\section{Numerical solutions of the model}

In our model different forms of asymmetry can be considered: countries may have asymmetric structural model parameters (model asymmetry), policymakers may have different preferences (preference asymmetry), policymakers may have different bargaining powers in negotiating cooperative agreements (power asymmetry) and, finally, shocks may asymmetrically hit countries (shock asymmetry).

By analyzing the different cases of asymmetries, we may compare some conclusions of Buti and Sapir (1998) and Beetsma et al. (2001), but now in a dynamic and possibly asymmetric model setting. Buti and Sapir (1998) argue that fiscal coordination is desirable when large symmetric shocks are present, while Beetsma et al. (2001) argue that fiscal coordination is desirable when there are asymmetric shocks, because fiscal authorities can internalize the spillovers connected with opposite fiscal policies.

\subsection{Symmetric baseline models}

The baseline parameters used in the simulations are listed in Table 1. Although countries are assumed to be symmetric with respect to all the structural form parameters, policymakers' preferences are not symmetric. The ECB's preference differs from that of the (identical) national governments (preference asymmetry). The ECB puts a larger weight on inflation stabilization than output gap stabilization. Fiscal players, on the other hand, are more concerned with output gap stabilization than inflation (rate) stabilization. As explained earlier, the ECB objectives concern EMU aggregate output gap and inflation while the fiscal players are only concerned about domestic output gap and inflation. Results from various empirical studies on the euro area suggest e.g. that the interest rate elasticity of output $\left(\gamma_{i}\right)$ lies in the range 0.1 to 0.3 (e.g. Angeloni et al. (2002) find a value of 0.19 ), that the instantaneous multiplier of fiscal policy $\left(\eta_{i}\right)$ is between 0.5 and 1 (European Commission (2001) uses a value of 0.5 in its model), that the competitiveness effect $\left(\delta_{i j}\right)$ and the elasticity w.r.t. foreign output gap $\left(\rho_{i j}\right)$ are somewhere around 0.2 and 0.3 , respectively (Hooper et al. (1998)). Considerable evidence also exists for the property that the output gap elasticity in the Phillips curve $\left(\zeta_{i}\right)$ is rel- 
atively small (Smets (2000) estimates a value of 0.18) and that there is some effect from foreign inflation rates $\left(\varsigma_{i j}\right)$ (Laxton et al. (1998)). For the symmetric baseline model we will consider two cases: the first base scenario (BS1) with a high elasticity w.r.t. foreign output, $\rho_{i j}=\rho=0.4$, reflecting strongly interdependent economies in terms of output gap, and the second base scenario (BS2) with $\rho_{i j}=\rho=0.2$, characterized by weakly interdependent economies.

Table 1 - Baseline parameters $(i, j \in\{1,2,3\}, i \neq j)^{17}$

\begin{tabular}{cccccc}
\hline$\eta_{i}=1$ & $\delta_{i j}=0.2$ & $\gamma_{i}=0.2$ & $\zeta_{i}=0.3$ & $\rho_{i j}=0.4$ & $\varsigma_{i j}=0.1$ \\
$\alpha_{i}=0.2$ & $\beta_{i}=0.4$ & $\chi_{i}=0.15$ & $\alpha_{E C B}=0.4$ & $\beta_{E C B}=0.2$ & $\chi_{E C B}=0.15$ \\
\hline
\end{tabular}

Given the parameters of Table 1, the matrix of reduced form coefficients in this first scenario $\left(L_{(1)}:=\left[\begin{array}{|l|l|l|}\hline D_{(1)} & E_{(1)} & M_{(1)} \\ \hline A_{(1)} & B_{(1)} & N_{(1)}\end{array}\right]\right.$ ) equals (the theoretical reduced form coefficients are derived in the Appendix):

$L_{(1)}=\left[\begin{array}{ccc|ccc|c|}\hline-0.2973 & 0.1486 & 0.1486 & 3.1622 & 2.4189 & 2.4189 & -1.6000 \\ 0.1486 & -0.2973 & 0.1486 & 2.4189 & 3.1622 & 2.4189 & -1.6000 \\ 0.1486 & 1.1828 & -0.2973 & 2.4189 & 2.4189 & 3.1622 & -1.6000 \\ \hline-0.1311 & 0.0405 & 0.0405 & 1.1351 & 0.9324 & 0.9324 & -0.6000 \\ 0.0405 & -0.1311 & 0.0405 & 0.9324 & 1.1351 & 0.9324 & -0.6000 \\ 0.0405 & 0.0405 & -0.1311 & 0.9324 & 0.9324 & 1.1351 & -0.6000 \\ \hline\end{array}\right.$

Since $E_{(1)}$ and $B_{(1)}$ contain only positive off-diagonal elements, the setting is characterized by positive fiscal externalities on the real output gaps (i.e. increases in the domestic fiscal deficit raise foreign output gaps) and negative fiscal externalities on the inflation rates (i.e. increases in the domestic fiscal deficit raise foreign inflation). Moreover, increases of domestic fiscal expenditures raise both the domestic real output gaps and inflation rates.

The matrix $L_{(2)}$ is computed for BS2 (with $\rho=0.2$ instead of $\rho=0.4$ ). It turns out that the parameter $\rho$ has a crucial effect on the elasticities in the submatrices $E_{(2)}$, $B_{(2)}, M_{(2)}$ and $N_{(2)}$. All elements of $L_{(2)}$ have the same sign as in $L_{(1)}$. However, the values in matrices $E_{(2)}$ and $B_{(2)}$ are substantially lower, which indicates that fiscal players' instruments have much less influence on real output gaps and inflation. Also the influence of the interest rate is limited compared with that in BS1 (matrices $M$ and $N)$. This relative importance of $\rho$ is not accidental as this parameter describes foreign output gap spillovers, which indirectly but to a large extent depend on foreign fiscal instruments, boosting their effects. The value of $\rho$ is therefore crucial in determining the foreign fiscal spillovers, which explains the relatively big differences between the matrices $L_{(1)}$ and $L_{(2)}$, and consequently between losses in both scenarios. Note also that spillovers spread themselves out of the entire monetary union through trade channels.

\footnotetext{
${ }^{17}$ In all the simulations we have used symmetric bargaining powers and a discount rate $(\theta)$ equal to 0.1 . Robustness of the results has been tested by many additional non-reported numerical simulations available upon request.
} 
In fact through secondary round initial spillovers will eventually return to the country of their origin as other countries start to import more as a result of the initial positive spillover. Moreover, these effects increase when the number increases.

$$
L_{(2)}=\left[\begin{array}{ccc|ccc|c|}
\hline-0.3492 & 0.1746 & 0.1746 & 1.2169 & 0.3439 & 0.3439 & -0.3810 \\
0.1746 & -0.3492 & 0.1746 & 0.3439 & 1.2169 & 0.3439 & -0.3810 \\
0.1746 & 0.1746 & -0.3492 & 0.3439 & 0.3439 & 1.2169 & -0.3810 \\
\hline-0.1452 & 0.0476 & 0.0476 & 0.3968 & 0.1587 & 0.1587 & -0.1429 \\
0.0476 & -0.1452 & 0.0476 & 0.1587 & 0.3968 & 0.1587 & -0.1429 \\
0.0476 & 0.0476 & -0.1452 & 0.1587 & 0.1587 & 0.3968 & -0.1429 \\
\hline
\end{array}\right.
$$

\subsection{Common Price Shock}

We first consider a common price shock $\left(p_{0}=[0.1,0.1,0.1]^{\prime}\right)$ that hits the whole EMU area (with an equal size). Optimal losses for BS1 are described in Table 2. ${ }^{18}$

\begin{tabular}{ccccccc}
\multicolumn{6}{c}{ Table 2 - BS1. Optimal losses for a common shock (multiplied by $\left.10^{8}\right)$} \\
\hline$\rho=0.4$ & $N C$ & $C$ & $F$ & $(1,2)$ & $(1,3)$ & $(2,3)$ \\
Country 1 & 24.7620 & 24.6479 & 24.7708 & 24.7755 & 24.7755 & 24.7487 \\
Country 2 & 24.7620 & 24.6479 & 24.7708 & 24.7755 & 24.7487 & 24.7755 \\
Country 3 & 24.7620 & 24.6479 & 24.7708 & 24.7487 & 24.7755 & 24.7755 \\
ECB & 54.1579 & 48.0783 & 54.5365 & 54.3463 & 54.3463 & 54.3463 \\
\hline
\end{tabular}

The only regime that results in optimal losses that are lower than those associated with the non-cooperative case is the full coordination solution (grand coalition $C$ ) between fiscal and monetary authorities (in more technical terms, full coordination is the only profitable regime). All forms of fiscal coordination are associated with negative performances (i.e. coalition members have losses higher than those that they achieve in the complete non-cooperative regime); hence, these coalitions are non-profitable. In this symmetric case, partial coordination of fiscal policies has a negative effect: partial coordination tends to aggravate the conflict with the excluded fiscal player and the ECB. It is easily verified that all the coalitional equilibriums coincide and that the full cooperative case $C$ is the single equilibrium; hence, $\mathrm{CNE}=\mathrm{SNE}=\mathrm{SNGE}=\mathrm{FCE}=C$. Table 3 describes the optimal losses for BS2. Compared with BS1, full cooperation is no longer the first best choice for the fiscal players, who would prefer to exclude the ECB from the full coalition in order to create the fiscal regime $F$. To better understand the reasons behind this change it is useful to study the macroeconomic adjustments of relevant variables presented in Figure 1 (both base scenarios under a common price shock). Panel (a) shows the non-cooperative regime and panel (b) the full cooperative case (because of the symmetry only the results for one country are reported).

\footnotetext{
${ }^{18} \mathrm{NC}$ indicates the non-co-operative regime, $C$ the full-co-operation regime, $F$ the coalition between all the fiscal authorities, and terms between brackets denote partial coalitions among fiscal authorities.
} 
Table 3 - BS2. Optimal losses for a common shock (multiplied by $10^{8}$ )

\begin{tabular}{ccccccc}
\hline$\rho=0.2$ & $N C$ & $C$ & $F$ & $(1,2)$ & $(1,3)$ & $(2,3)$ \\
Country 1 & 24.5853 & 24.6741 & 24.5818 & 24.5865 & 24.5865 & 24.5766 \\
Country 2 & 24.5853 & 24.6741 & 24.5818 & 24.5865 & 24.5766 & 24.5865 \\
Country 3 & 24.5853 & 24.6741 & 24.5818 & 24.5766 & 24.5865 & 24.5865 \\
ECB & 49.0913 & 48.1967 & 48.9489 & 49.0247 & 49.0247 & 49.0247 \\
\hline
\end{tabular}

Observing a common price shock, fiscal authorities try to improve competitiveness vis-à-vis the other countries with restrictive fiscal policies, but since all the countries follow the same policy the final losses in the non-cooperative regime are higher than in the cooperative one for BS1. Therefore, non-cooperative fiscal policies tend to induce a recession, and the ECB reacts by cutting the nominal interest rate to stimulate the economies. The different losses between the two regimes are mainly associated with the different management of the policies. Output gaps and inflation rates adjust practically in the same manner, but policy strategies are largely different. In the non-cooperative regime, in fact, fiscal authorities tend to neutralize mutual effects on competitiveness, whereas the ECB tends to neutralize the deflationary and recessive effects of fiscal policies. ${ }^{19}$ In the cooperative regime all policymakers internalize the negative externalities from their policy management. The cooperative regime disciplines the management of the fiscal policies so that countries pursue moderate fiscal expansions and end up with small deficits.

Figure 1
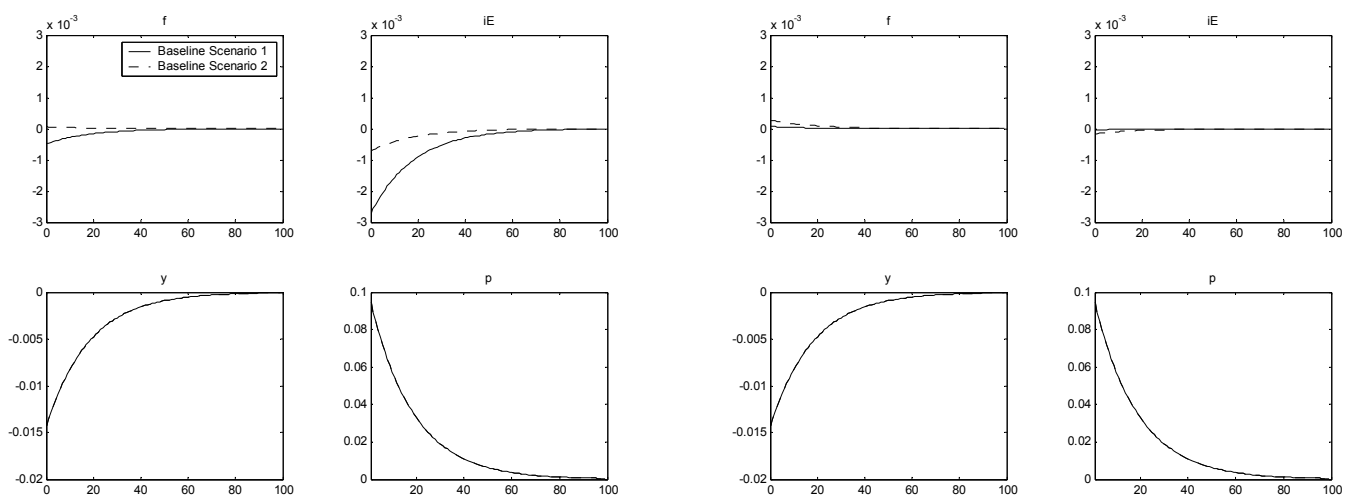

(a) Non-cooperative regime $(\mathrm{NC})$

(b) Full cooperation (C)

In BS2 both fiscal and monetary policies are more moderate in the non-cooperative regime, compared to BS1. The policies of fiscal players are in the non-cooperative regime

\footnotetext{
${ }^{19}$ With a (symmetric) positive price shock $\left(p_{0}=[0.1,0.1,0.1]^{\prime}\right)$ fiscal policy is restrictive (a surplus) and monetary policy is expansionary (a negative interest-rate differential), while with a (symmetric) negative price shock $\left(p_{0}=[-0.1,-0.1,-0.1]^{\prime}\right)$, we have the same (optimal) losses but with opposite policies: a restrictive monetary policy and an expansionary fiscal policy. In the latter case there is an expenditure bias that can be reduced by co-ordinating fiscal policies.
} 
more moderate than in the full cooperative one so that losses become in the latter case higher than in the former one. Therefore, full cooperation is not any longer an equilibrium for any of the mechanisms considered. It is worth noticing that there is almost no difference in output gaps and price adjustments between BS1 and BS2. It means that differences in losses are to a great extent induced by differences in stabilization policies. In other words an increased control effort in the non-cooperative regime just leads to higher negative fiscal spillovers. This is a strong argument in favour of coordination.

The strong difference between BS1 and BS2 is not accidental. Robustness analysis in this symmetric setting shows that, indeed, parameter $\rho$ is crucial in the case of a symmetric price shock. For more interdependent economies in terms of output (lower value of $\rho$ ). full cooperation is more profitable than non-cooperation. However, when economies are relatively less interdependent in terms of output the outcome for fiscal players is opposite. One dimensional variations of other parameters do not affect substantially the above result.

In the above numerical simulations we have mainly discussed ex-post policy coordination. However, the complex situation which emerged in Table 3 suggests that also different forms of ex-ante coordination should be studied. In fact, fiscal policy coordination $(F)$ assures for all fiscal players better results than those for the non-cooperative regime $(N C)$. However, $F$ is not a $\mathrm{CNE}$ as it is neither externally nor internally stable. The ECB has an incentive to join the fiscal coalition (lack of external stability) and each fiscal player has an incentive to deviate and play as a singleton when the other two fiscal players are in partial coalition (lack of internal stability). No other regime turns out to be a CNE of this game, consequently players act non-cooperatively.

Since the $N C$-solution is Pareto-inferior with respect to fiscal cooperation $F$, it is interesting to look for different mechanisms that support coordination. The inefficiency that emerges from Table 3 follows from the mechanism considered in the coalition formation and may be eliminated under different procedures. The institutional cooperative design, in which policymakers act, determines the rules of the coalition formation process (Ecchia and Mariotti (1998)). For instance, using the algorithm for the SNGE (to be found in the Appendix) the resulting equilibrium will be the desired fiscal coordination $(F)$ since each proponent (countries $1,2,3$ ) has an incentive to propose this coalition it is the only one that will be accepted by the other countries as a better solution than non-cooperation. In addition countries know that there is no possibility that a partial coalition emerges as an ultimate equilibrium; therefore, they are aware that any noncooperative strategy would end up in the $N C$-regime. In this example we also have that $\mathrm{SNE}=\mathrm{FCE}=F$. On the other hand, a mechanism implying the $\mathrm{FCE}$ requires more information than the one supporting the SNGE or the CNE. For instance, the FCE is not compatible with an non-transparent central bank or with an environment where credible information about the state of the economies is not available. If the member states themselves have to provide information about their economy they could try to use this information strategically, and, therefore, this is incompatible with the FCE institutional design (a similar observation can be made for information provided by the ECB). 
This example indicates that, even when coordination gains are present, cooperative solutions do not necessarily emerge as an equilibrium of the game. Different institutional designs (ex-ante coordination) imply different equilibriums. Therefore, rules, procedures and available information are sometimes crucial to improve cooperative solutions and to raise the welfare of all the policymakers by avoiding a free-riding behaviour.

Note that the above analysis matches the case studied by Buti and Sapir (1998), where a common (price) shock is applied. The results obtained for BS2 confirm their conclusion that in the case of a common symmetric shock fiscal coordination emerges as an equilibrium. However, for relatively more integrated economies (as in BS1) full cooperation turns out to be optimal. Hence, both the degree of integration and the symmetric character of the shock determines the scope for cooperation.

\subsection{Anti-Symmetric Shock}

We consider a country-specific price shock that affects the prices in countries 1 and 3 in an opposite manner (an anti-symmetric country-specific shock, $p_{0}=[0.1,0,-0.1]^{\prime}$ ). Optimal losses for the various regimes in BS1 are reported in Table $4 .{ }^{20}$ Optimal losses presented in Table 4 are multiplied by a factor $10^{6}$, therefore they are much higher than those in Tables 2 and 3. These differences are by far higher than the differences between BS1 and BS2, where model parameters are changed. This indicates that in our model the nature of the shock is much more important than structural asymmetries on the competitiveness parameter $\rho$.

\begin{tabular}{ccccccc}
\multicolumn{6}{c}{ Table 4 - Optimal losses for country-specific shock (multiplied by $\left.10^{6}\right)$} \\
\hline & $N C$ & $C$ & $F$ & $(1,2)$ & $(1,3)$ & $(2,3)$ \\
Country 1 & 16.1105 & 8.0582 & 8.0582 & 10.2819 & 8.0582 & 17.1070 \\
Country 2 & 0 & 0 & 0 & 2.6283 & 0 & 2.6283 \\
Country 3 & 16.1105 & 8.0582 & 8.0582 & 17.1070 & 8.0582 & 10.2819 \\
ECB & 0 & 0 & 0 & 0.0430 & 0 & 0.0430 \\
\hline
\end{tabular}

The most evident feature of Table 4 is that there are no differences in optimal losses between the grand coalition $C$, the fiscal coalition $F$, and the partial coalition $(1,3)$. This occurs because the fiscal policy of the first country is exactly offset by the fiscal policy of the third country, due to the model symmetry and the preference symmetry among fiscal authorities. ${ }^{21}$ More in detail, in regimes where countries 1 and 3 are either both in the same coalition or both outside, due to the equal sizes of the perfectly opposite shocks, the ECB and country 2 do not affect the dynamics of the game since changes in the common nominal interest rate equally affect all the prices and output gaps. This changes when partial fiscal coalitions with country 2 are formed, even in this symmetric setting. With the partial fiscal coalitions $(1,2)$ and $(2,3)$ all the players, including the ECB, are directly affected in their optimal policies and losses. Coalitions including both

\footnotetext{
${ }^{20}$ The results for the BS2 are comparable to those for BS1, we report and discuss only the first baseline.

${ }^{21}$ See van Aarle et al. (2002a) for a more detailed description of this mechanism in a two-country model.
} 
countries 1 and 3 are clearly equilibriums of the game since they correspond to the first best strategies for all the players. Hence, $\mathrm{FCE}=\mathrm{SNGE}=\mathrm{SNE}=C$ and the Rational Feasible Coalitions set of $\mathrm{FCE}=C, F,(1,3) .{ }^{22}$

Figure 2 shows the paths of the control variables after the country-specific shock for $\mathrm{BS} 1$ and BS2. The results for BS2 are similar to those of BS1.

Figure 2
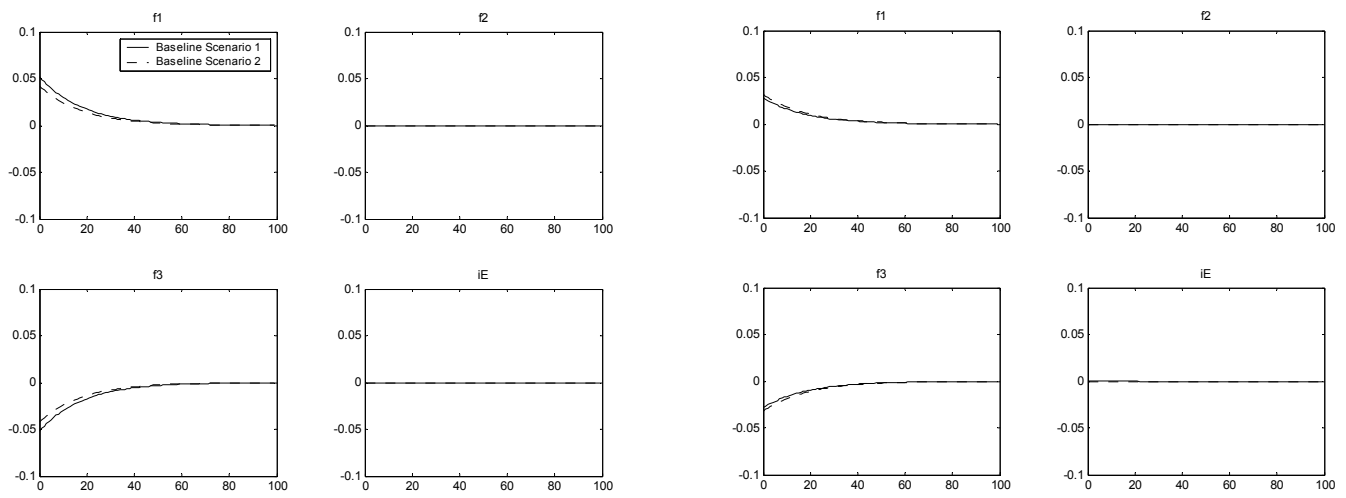

(a) Non-co-operative regime (NC)

(b) Regimes C,F,(1,3)

Like in the case of a common price shock/supply shock, non-cooperative policies are less active in BS2 than BS1, whereas in the case of cooperation the opposite occurs. In contrast to the common shock case, the outcome of the coalition formation process does not change between BS1 and BS2. Figure 2 shows that symmetries have a neutralizing effect and tend to compensate the effects of the policymakers' actions. Therefore, cooperation helps in reducing the losses from too expansionary (restrictive) fiscal policies: in the cooperative case country 1 has a smaller deficit and country 3 a smaller surplus than in the non-cooperative case. In this way negative fiscal externalities are internalized and, therefore, partially reduced. Because of the perfect structural symmetry of the model, country 2 and the ECB are not affected at all by the anti-symmetric shocks in country 1 and 3.

The asymmetric country-specific shock analyzed in Table 4 is the case which Beetsma et al. (2001) analyze and find that fiscal coordination is desirable. We confirm their result: fiscal authorities internalize the negative effects of opposite policies with coordination. But, we also find that, in this symmetric setting, no further gains are associated with full cooperation $C$, which is confirmed by Figure 2 (no more effects to internalize).

\footnotetext{
${ }^{22}$ The full coalition $C$ is the sole SNGE as it is assumed according to the algorithm in the Appendix that in the case of equal losses players will choose that coalition which contains the highest number of players. A similar reasoning can be applied for the FCE, where it is assumed that in the case where the Rational Feasible Coalitions set consists of more than one regime, the players will look for an exogenous system to choose the final coalition (see the algorithm to compute SNE, SNGE and FCE in the Appendix available on internet (see footnote 7$)$ ).
} 
The above examples seem to advocate a need for coordination. We can distinguish two cases. First, when a common price shock is considered, full coordination or fiscal coordination of policies is required to internalize the externalities arising from excessive spendings. Second, when anti-symmetric country-specific shocks occur, coordination needs become weaker since only fiscal coordination among those countries that are hit by the shocks, is needed. Third, in the case of asymmetric shocks (not shown) the room for cooperation is further reduced as there is even more difference in the optimal policies from the perspective of the country affected by the shock and the other countries that do not experience such a shock.

Negotiation mechanisms and their outcomes are clear in the above example. However, less trivial cases may arise when more asymmetries are considered.

\subsection{Structural Asymmetric Setting}

The parameters of Table 5 can be interpreted as a setup where a relatively closed country (country 1) faces two relatively open countries that are relatively more sensitive to foreign output and price changes. In such a context we consider the following country-specific price shock: $p_{1}(0)=0.1, p_{2}(0)=0.075$, and $p_{3}(0)=0.05$.

Table 5 - An example of a structural asymmetric setting

\begin{tabular}{llllll}
\hline$\eta_{1}=1$ & $\delta_{12}=0.1$ & $\gamma_{1}=0.2$ & $\zeta_{1}=0.3$ & $\rho_{12}=0.3$ & $\varsigma_{12}=0$ \\
$\eta_{2}=1$ & $\delta_{13}=0.1$ & $\gamma_{2}=0.2$ & $\zeta_{2}=0.3$ & $\rho_{13}=0.3$ & $\varsigma_{13}=0$ \\
$\eta_{3}=1$ & $\delta_{21}=0.3$ & $\gamma_{3}=0.2$ & $\zeta_{3}=0.3$ & $\rho_{21}=0.5$ & $\varsigma_{21}=0.2$ \\
& $\delta_{23}=0.3$ & & & $\rho_{23}=0.5$ & $\varsigma_{23}=0.1$ \\
& $\delta_{31}=0.3$ & & & $\rho_{31}=0.5$ & $\varsigma_{31}=0.2$ \\
& $\delta_{32}=0.3$ & & & $\rho_{32}=0.5$ & $\varsigma_{32}=0.1$ \\
\hline
\end{tabular}

The asymmetries imply that spillovers are not longer symmetric across the monetary union. This is also seen in the matrix $\left(L_{3}\right)$ which corresponds to Table 5 . It features asymmetric positive fiscal spillovers for output gaps and inflation rates and a mixed (asymmetric positive/negative) pattern of price spillovers. Also elasticity of output gap and inflation w.r.t. interest rate is asymmetric:

$$
L_{3}=\left[\begin{array}{ccccccc}
0.9396 & -0.4698 & -0.4698 & 2.3364 & 0.8178 & 0.7788 & -2.0805 \\
1.8054 & -1.2140 & -0.5914 & 3.2710 & 3.2877 & 2.2808 & -2.9262 \\
1.8054 & -0.5914 & -1.2140 & 3.5514 & 2.6001 & 3.3267 & -2.9262 \\
0.2319 & -0.1409 & 0.1409 & 1.3087 & 0.9060 & 0.9060 & -0.6242 \\
0.6644 & -0.4671 & 0.2473 & 2.0134 & 1.8729 & 1.6842 & -1.1141 \\
0.6644 & -0.2473 & -0.4671 & 2.0134 & 1.6842 & 1.8729 & -1.1141
\end{array}\right]
$$

The resulting optimal losses are described in Table 6 . Country 3 has by far the highest losses in all regimes, whereas country 2 has the lowest (except in the partial coalition $(2,3)$ ). As countries 2 and 3 are identical, an explanation of these outcomes is to be found in the asymmetry of the shocks and the different adjustment dynamics 
produced by them. Due to the assumed price shock $p_{0}=[0.1,0.075,0.05]^{\prime}$ country 1 has a comparative price disadvantage w.r.t. to countries 2 and 3. This causes a relatively high instability in output, especially for country 3 , which is an inflation importer. Moreover, the common monetary policy is based on an aggregate macroeconomic variable, hence it tends to stabilize the average. Therefore, its policy is more in line with the situation in country 2 which shock is the closest to the average. Moreover, for country 2 externalities of countries 1 and 3 tend to compensate each other to a large extent. Consequently this player features the lowest losses (except in the regime $(2,3)$ in spite of the fact that its shock is larger than the shock incurred by country 3 . When country 2 creates a partial fiscal coalition with country 3, it will follow the policy optimal for the coalition. Consequently for country 2 this policy will be less in line with the ECB money management, what explains its relatively high loss in this regime.

\begin{tabular}{ccccccc}
\multicolumn{6}{c}{ Table 6 - Asymmetric economic structure and country-specific shock } \\
\hline & $N C$ & $C$ & $F$ & $(1,2)$ & $(1,3)$ & $(2,3)$ \\
Country 1 & 0.4305 & 0.5041 & 0.5203 & 0.3830 & 0.5848 & 0.4693 \\
Country 2 & 0.1621 & 0.1810 & 0.1977 & 0.1563 & 0.1442 & 0.5383 \\
Country 3 & 1.9440 & 0.9378 & 0.9824 & 1.9253 & 1.0272 & 1.3843 \\
ECB & 0.2695 & 0.2982 & 0.2931 & 0.2710 & 0.2915 & 0.2722 \\
\hline
\end{tabular}

As far as coalition formation mechanisms are concerned there is no CNE. Only for country 3, fiscal and full cooperation is better than non-cooperation. Partial fiscal cooperation $(1,2)$ is profitable for fiscal players (with respect to $N C$ ), however it is not externally stable as country 3 has an incentive to join and create the fiscal coalition regime $F$. Other partial fiscal coalitions $(1,3)$ and $(2,3)$ do not meet the profitability condition. On the other hand, in the farsighted FCE-mechanism the regime $(1,2)$ emerges as an equilibrium. It comes from the fact that country 3 , being aware that the final outcome of its deviation is the non-profitable regime $N C$, does not want to join the coalition $(1,2)$. Also, for any order of proposal both the SNE and the SNGE result in the coalition $(1,2)$. Figure 3 displays the adjustments of control and output variables in the non-cooperative and $(1,2)$ regimes. Under non-cooperation (left-hand panel), country 1 has an expansionary policy since its output declines due to the unfavourable terms of trade and highest price shock, whereas country 3 pursues a comparatively very restrictive fiscal policy, as an inflation importer. Country 2 is somewhere in between, with initially pursuing a restrictive fiscal policy, that eventually turns into an expansionary one. Graphs in the right-hand side panel of Figure 3 present the difference between regimes $(1,2)$ and $N C$. Partial fiscal cooperation between countries 1 and 2 leads to more moderate stabilization policies for all countries and also for the ECB. However, gains from using a smaller control effort are offset by (in general) more volatile output gap and price adjustments. Summarizing, this is again the example of internalized externalities from excessive stabilization policies in the non-cooperative regime.

\footnotetext{
${ }^{23}$ Losses multiplied by factor $10^{6}$.
} 
Figure 3 - Adjustments of controls and output variables for $N C$ and $(1,2)$ regimes
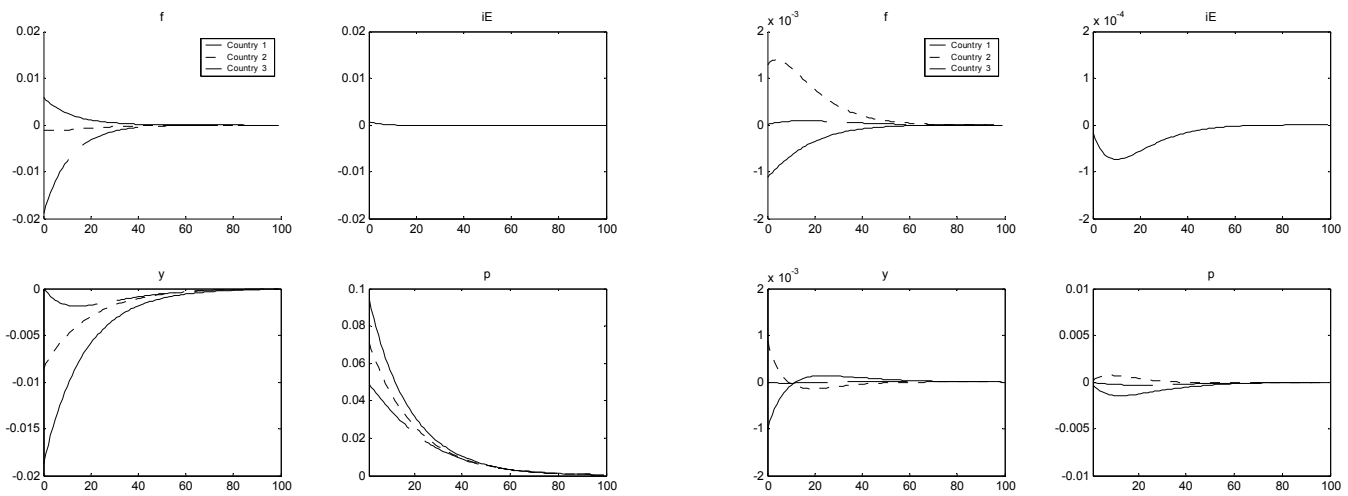

(a) Non-co-operative regime $(\mathrm{NC})$

(b) Partial fiscal co-operation $(1,2)$

In the next example we study in more detail the difference between the SNGE and the SNE mechanisms. Again we consider the structural asymmetric setting, but also with the bargaining power asymmetry of the players in the coalitions. It is assumed that country 3 has always a lower bargaining power when it cooperates with the (an) other policymaker(s). ${ }^{24}$ More in detail, country 3 is assumed to have a bargaining power equal to $\tau_{3}=\frac{1}{5}$ in the grand coalition regime (while the other players share the rest, i.e. each of them has a bargaining power equal to $\left.\tau_{1,2, E}=\frac{\left(1-\frac{1}{5}\right)}{3}\right)$, country 3's bargaining power is assumed to be equal to $\frac{1}{4}$ in the fiscal cooperation regime (others $\frac{3}{8}$ ), and it is assumed to be equal to $\frac{1}{3}$ when this country cooperates with only one of the other countries $\left(\frac{2}{3}\right)$. Of course, the (optimal) losses associated with the non-cooperative regime and the coalition between country 1 and country 2 are the same as in the previous case. In this scenario, all the countries are asymmetric through the combination of the power and shock asymmetries (at least when shock asymmetry occurs). Moreover, power asymmetry is reflected in the ECB loss function where country 3's weight is assumed to be $\sigma_{3}=\frac{1}{4}$ and weights of the other countries are equal: $\sigma_{1}=\sigma_{2}=\frac{3}{8}$, which means that the ECB is relatively more concerned about the inflation and output than the latter two players. The following structural asymmetries are assumed: ${ }^{25} \delta_{31}=\delta_{32}=0.4$; $\rho_{31}=\rho_{32}=0.6$. This set of parameters can be interpreted as a setup where country 3 is relatively small. In such a context we consider the anti-symmetric price shock: $p_{1}(0)=0.1, p_{2}(0)=0$, and $p_{3}(0)=-0.1$.

The resulting losses are described in Table 7 . As in the previous example country 3 has by far the highest losses in all regimes, whereas country 2 has the lowest. Country 1 obtains the lowest loss in the partial coalition $(1,3)$, country 2 and the ECB in the non-cooperative regime, and country 3 in the full coalition $C$. Note that any coalition

\footnotetext{
${ }^{24}$ The bargaining power of a country can be assumed to be an increasing function of its relative size (e.g. the share of its GDP with respect to the aggregate GDP of the EMU).

${ }^{25}$ All other parameters as in the BS1.
} 
containing country 2 is impossible. In fact, it is partial coalition $(1,3)$, which emerges as the CNE. It is the first best choice for country 1 and the second best choice for country 3. Therefore, in this example, the CNE-mechanism is quite effective from the welfare point of view for countries 1 and 3. However, the SNE-mechanism, in which players have limited information only to own losses, leads, for the standard order of players $[\mathrm{C} 1, \mathrm{C} 2, \mathrm{C} 3, \mathrm{ECB}]$, to the non-cooperative regime.

\begin{tabular}{|c|c|c|c|c|c|c|}
\hline & $N C$ & $C$ & $F$ & $(1,2)$ & $(1,3)$ & $(2,3)$ \\
\hline Country 1 & 22.7909 & 7.8637 & 6.9864 & 11.6036 & 6.6461 & 20.6860 \\
\hline Country 2 & 0.0361 & 0.5010 & 0.8137 & 3.8812 & 0.3890 & 7.1981 \\
\hline Country 3 & 83.9346 & 19.9487 & 22.1967 & 84.7294 & 21.9766 & 33.6221 \\
\hline$E C B$ & 0.1354 & 0.1364 & 1.0285 & 0.3784 & 1.4610 & 0.3340 \\
\hline
\end{tabular}

The SNE-negotiations start with country 1 which proposes the partial coalition $(1,3)$. Country 3 rejects this proposal and instead proposes the full coalition, as its first best choice. However, this proposal is rejected by country 1 , which in this place proposes the fiscal coalition $F$. But country 2 does not want to belong to any coalition; therefore, when its turn comes, it rejects $F$ and leaves the negotiation process. There is no other coalition to create and the final outcome is the non-cooperative regime $N C$. This example shows that the SNE-mechanism can lead to regimes which are not efficient from the the point of view of players who possess the right to make first proposals. This deficiency comes from the fact that the SNE-mechanism is adopted in the situation when no perfect information is available. When players know only own losses and are risk-averse (as assumed) they commit themselves to follow the SNE-algorithm; however, this mechanism is unable to always deliver a better outcome than the CNE. The SNGE-mechanism is based on the same rules as the SNE, but we remove the assumption of imperfect information. When players know each others' losses they are able to act strategically and the SNGE-game shall be solved by backward induction. In other words, at every moment each player takes into account further consequences of her actions. Therefore, in the example in Table 7 the partial coalition $(1,3)$ is immediately reached by the SNGE-mechanism. It happens because player 3 does not reject the initial proposal of player 1 as it is obvious, that regimes $C$ and $F$ can never be reached. Note that because decisions in the SNGE-game are made strategically this mechanism is to some extent comparable to the FCE-one. In fact, in this case $\mathrm{CNE}=\mathrm{SNGE}=\mathrm{FCE}=(1,3)$.

This comparison between the SNE and the SNGE stresses the importance of information availability in a monetary union. It is especially significant in a structurally asymmetric setting, which is closer to the real-world situation, and where optimal policies and the optimal outcomes become more complex. There are three factors which are crucial in determining the coalitional equilibrium (or equilibria) of the game: an asymmetry of shocks, a structural asymmetry and resulting fiscal and inflation spillovers. In the cases that were analyzed the asymmetry of shocks contributes most to the relative

\footnotetext{
${ }^{26}$ Losses multiplied by factor $10^{6}$.
} 
differences between losses of players and structural asymmetry plays a secondary role. It indicates that mechanisms of coordinations in a monetary union need to be developed even when countries are relatively highly integrated and structurally symmetric, but when there is still a risk of asymmetric shocks.

\section{Concluding remarks}

In this paper we have studied the institutional design of the coordination of macroeconomic stabilization policies within the EMU and its consequences on macroeconomic outcomes and policies. We have taken into account both ex-ante and ex-post coordination. Ex-ante coordination is related to the institutional framework, the coordination procedure, and the design of policy rules within the $\mathrm{E}(\mathrm{M}) \mathrm{U}$, whereas ex-post coordination takes place from the current state of affairs and concerns the actual policy decisions of the national governments and the ECB.

Numerical simulations in a simplified three-country monetary union setting illustrate the most important aspects of our approach. In our simulations different kinds of spillovers and asymmetries have been considered since fiscal policy coordination is strongly connected with the externalities (fiscal spillovers) and asymmetries that are present in the economy. From the simulations some general and to a large extent robust conclusions can be drawn when several symmetries (but not all) are assumed.

In the case of a common shock and symmetric countries two main results can be derived from our model. When countries are relatively highly integrated in terms of output spillovers, fiscal coordination is counterproductive but full policy coordination is desirable. By contrast, in the case when output spillovers are lower, fiscal cooperation turns out to be optimal. For a country-specific (asymmetric) shock, fiscal coordination is desirable and full policy coordination is not associated with any extra gain in the policymakers' welfare. Our results add new features to the debate between Buti and Sapir (1998) and Beetsma et al. (2001) on the effects of coordination in the presence of different types of shocks. Fiscal coordination can be deficient in the case of a common shock (as suggested by Beetsma et al. (2001)). In this situation the coordination among all policymakers improves the performance. The reason for this is that full cooperation reduces the tensions between the ECB and the governments in pursuing different priorities, and therefore, it reduces the costs of contrasted policies. On the contrary, fiscal cooperation increases such tensions since it increases the clash among the institutions that pursue different priorities. However, when output spillovers are relatively low, fiscal cooperation turns out to be better than full cooperation.

When anti-symmetric shocks are considered, fiscal coordination improves the performance by internalizing the traditional negative fiscal externalities (as suggested by Beetsma et al. (2001)) and full policy coordination doesn't produce further gains in the policymakers' welfare since, in this case, there are no further externalities associated with the separate management of the fiscal and monetary policies.

Our approach also shows that it is of crucial importance to consider how coalitions are formed (ex-ante coordination). Following the recent literature, different coalition 
formation mechanisms can be associated with different institutional settings where policymakers act. In fact, it can occur that, even if a cooperative solution assures for all the policymakers a lower loss than in the case of a non-cooperative solution, it does not emerge as an equilibrium of the game because of free-rider behaviour which generally leads to non-cooperative solutions according to the CNE-mechanism (even if cooperation is Pareto-superior to non-cooperation). In general, mechanisms where policymakers share more information (as the SNGE-mechanism (hierarchical), and the FCE-mechanism (farsighted)), are more likely to support cooperative solutions avoiding free-riding behaviour than the traditional CNE-mechanism, which, however, seems to be the concept that represents best the current EMU context. It turns out that it is also possible to design a hierarchical procedure similar to the SNGE, which can be applied in the case where there is no interchange of information between players. In many examples the equilibrium obtained with the SNE-mechanism was the same as the SNGE equilibrium. It is not, however, a general rule, but again indicates that it may be very profitable to look for proper mechanisms of policy coordination, especially when little common information is available.

The coordination of economic policies seems to be more difficult when the number and size of externalities become large. In this case, externalities are often associated with negative effects irrespective of the kind of shocks or fiscal spillovers considered. The ex-post fiscal coordination results are strongly connected with the size and sign of externalities (fiscal spillovers) that are present in the economy. However, results under considerable asymmetries seem to be less robust, and, therefore, they have to be interpreted with caution.

A possible extension of the analysis concerns the introduction of outside-monetaryunion countries. This is a crucial issue as currently three EU Countries do not participate in the EMU and the group of Central and Eastern European Countries entered on the $1^{\text {st }}$ of May, 2004 the EU. It will also allow, among others, to study interactions between the EU and the USA economies, since significant externalities may be present in this context. 


\section{Appendix}

\section{Reduced form of the model}

Defining matrices $\eta:=\left[\begin{array}{cccc}\eta_{1} & 0 & \ldots & 0 \\ 0 & \eta_{2} & \ldots & 0 \\ \ldots & \ldots & \ldots & \ldots \\ 0 & 0 & \ldots & \eta_{n}\end{array}\right], \gamma:=\left[\begin{array}{cccc}\gamma_{1} & 0 & \ldots & 0 \\ 0 & \gamma_{2} & \ldots & 0 \\ \ldots & \ldots & \ldots & \ldots \\ 0 & 0 & \ldots & \gamma_{n}\end{array}\right], \rho:=\left[\begin{array}{cccc}0 & \rho_{12} & \ldots & \rho_{1 n} \\ \rho_{21} & 0 & \ldots & \rho_{2 n} \\ \ldots & \ldots & \ldots & \ldots \\ \rho_{n 1} & \rho_{n 2} & \ldots & 0\end{array}\right]$,

$\zeta:=\left[\begin{array}{cccc}\zeta_{1} & 0 & \ldots & 0 \\ 0 & \zeta_{2} & \ldots & 0 \\ \ldots & \ldots & \ldots & \ldots \\ 0 & 0 & \ldots & \zeta_{n}\end{array}\right], \varsigma:=\left[\begin{array}{cccc}0 & \varsigma_{12} & \ldots & \varsigma_{1 n} \\ \varsigma_{21} & 0 & \ldots & \varsigma_{2 n} \\ \ldots & \ldots & \ldots & \ldots \\ \varsigma_{n 1} & \varsigma_{n 2} & \ldots & 0\end{array}\right], \delta:=\left[\begin{array}{cccc}-\sum_{i \in \bar{N} / 1} \delta_{1 i} & \delta_{12} & \ldots & \delta_{1 n} \\ \delta_{21} & -\sum_{i \in \bar{N} / 2} \delta_{2 i} & \ldots & \delta_{2 n} \\ & \ldots & \ldots & \ldots \\ \delta_{n 1} & \delta_{n 2} & \ldots & -\sum_{i \in \bar{N} / n} \delta_{n i}\end{array}\right]$

and $\iota_{n}:=\left[\begin{array}{c}1 \\ 1 \\ 1 \\ \cdots \\ 1\end{array}\right]$, the structural form of the model can be rewritten as:

$$
\left\{\begin{array}{l}
x(t)=-\gamma \iota_{n} i_{u}(t)+\eta f(t)+\gamma \dot{p}(t)+\delta p(t)+\rho x(t) \\
\dot{p}(t)=\zeta x(t)+\varsigma \dot{p}(t), p(0)=p_{0}
\end{array}\right.
$$

Therefore, by solving the inflation equation, $\dot{p}(t)=(I-\varsigma)^{-1} \zeta x(t)$, and plugging this result in the output gap equation, we get: $x(t)=-\gamma \iota_{n} i_{u}(t)+\eta f(t)+\gamma(I-\varsigma)^{-1} \zeta x(t)+$ $\delta p(t)+\rho x(t)$, from which we obtain the reduced form for the real output gaps:

$$
x(t)=\left(I-\gamma(I-\varsigma)^{-1} \zeta-\rho\right)^{-1}\left(-\gamma \iota_{n} i_{u}(t)+\eta f(t)+\delta p(t)\right)
$$

and for the inflation rates:

$$
\dot{p}(t)=(I-\varsigma)^{-1} \zeta\left(I-\gamma(I-\varsigma)^{-1} \zeta-\rho\right)^{-1}\left(-\gamma \iota_{n} i_{u}(t)+\eta f(t)+\delta p(t)\right)
$$

Rearranging:

$$
\left[\begin{array}{c}
x(t) \\
\dot{p}(t)
\end{array}\right]=L\left[\begin{array}{c}
p(t) \\
f(t) \\
i_{u}(t)
\end{array}\right]=\left[\begin{array}{ccc}
D & E & M \\
A & B & N
\end{array}\right]\left[\begin{array}{c}
p(t) \\
f(t) \\
i_{u}(t)
\end{array}\right]
$$


where:

$$
\begin{gathered}
D:=\left(I-\gamma(I-\varsigma)^{-1} \zeta-\rho\right)^{-1} \delta \\
E:=\left(I-\gamma(I-\varsigma)^{-1} \zeta-\rho\right)^{-1} \eta \\
M:=-\left(I-\gamma(I-\varsigma)^{-1} \zeta-\rho\right)^{-1} \gamma \iota_{n} \\
A:=(I-\varsigma)^{-1} \zeta\left(I-\gamma(I-\varsigma)^{-1} \zeta-\rho\right)^{-1} \delta \\
B:=(I-\varsigma)^{-1} \zeta\left(I-\gamma(I-\varsigma)^{-1} \zeta-\rho\right)^{-1} \eta \\
N:=-(I-\varsigma)^{-1} \zeta\left(I-\gamma(I-\varsigma)^{-1} \zeta-\rho\right)^{-1} \gamma \iota_{n}
\end{gathered}
$$

we can rewrite the reduced form equations for real outputs as:

$$
\left\{\begin{array}{l}
x_{1}(t)=: L_{1} z(t) \\
\cdots \\
x_{n}(t)=: L_{n} z(t) \\
\dot{p}_{1}(t)=: L_{n+1} z(t) \\
\cdots \\
\dot{p}_{n}(t)=: L_{2 n} z(t)
\end{array}\right.
$$

where $L_{i}$ is the $i$ th row of matrix $L$ and $z^{\top}(t):=\left[p_{1}(t), p_{2}(t), \ldots p_{n}(t), f_{1}(t), f_{2}(t), \ldots f_{n}(t), i_{u}(t)\right]$. Thus, government $i$ 's loss function becomes:

$$
\begin{gathered}
J_{i}\left(t_{0}\right)=\frac{1}{2} \int_{t_{0}}^{\infty}\left\{\alpha_{i} \dot{p}_{i}^{2}(t)+\beta_{i} x_{i}^{2}(t)+\chi_{i} f_{i}^{2}(t)\right\} e^{-\theta\left(t-t_{0}\right)} d t= \\
=\frac{1}{2} \int_{t_{0}}^{\infty}\left\{z^{\top}(t)\left(\alpha_{i} L_{n+i}^{\top} L_{n+i}+\beta_{i} L_{i}^{\top} L_{i}+\chi_{i} e_{n+i}^{\top} e_{n+i}\right) z(t)\right\} e^{-\theta\left(t-t_{0}\right)} d t= \\
=\frac{1}{2} \int_{t_{0}}^{\infty}\left\{z^{\top}(t) M_{i} z(t)\right\} e^{-\theta\left(t-t_{0}\right)} d t, \quad M_{i} \in \mathbb{R}^{(2 n+1) \times(2 n+1)}
\end{gathered}
$$

where $e_{i} \in \mathbb{R}^{2 n+1}$ is a vector with all entries equal to zero, except for entry $i$ that is equal to one.

Similarly, we can rewrite the ECB's loss function as:

$$
\begin{aligned}
J_{E C B}= & \frac{1}{2} \int_{0}^{\infty}\left\{\alpha_{E C B}\left(\sum_{i=1}^{n} \sigma_{i} \dot{p}_{i}(t)\right)^{2}+\beta_{E C B}\left(\sum_{i=1}^{n} \sigma_{i} x_{i}(t)\right)^{2}+\chi_{E C B} i_{u}^{2}(t)\right\} e^{-\theta\left(t-t_{0}\right)} d t= \\
= & \frac{1}{2} \int_{t_{0}}^{\infty} z^{\top}(t)\left\{\begin{array}{c}
\alpha_{E C B}\left(\sum_{i \in \bar{N}} \sigma_{i} L_{n+i}\right)^{\top}\left(\sum_{i \in \bar{N}} \sigma_{i} L_{n+i}\right)+ \\
+\beta_{E C B}\left(\sum_{i \in \bar{N}} \sigma_{i} L_{i}\right)^{\top}\left(\sum_{i \in \bar{N}} \sigma_{i} L_{i}\right)+\chi_{E C B} e_{2 n+1}^{\top} e_{2 n+1}
\end{array}\right\} z(t) e^{-\theta\left(t-t_{0}\right)} d t \\
& =\frac{1}{2} \int_{t_{0}}^{\infty}\left\{z^{\top}(t) M_{E C B} z(t)\right\} e^{-\theta\left(t-t_{0}\right)} d t \quad M_{E C B} \in \mathbb{R}^{(2 n+1) \times(2 n+1)}
\end{aligned}
$$




\section{The basic algorithm to derive the game solutions}

Similar to the computations in Appendix A of van Aarle et al. (2002a) the algorithm is described by the following 5 steps.

1. Factorize matrices $M_{i}$ for any country or the central bank $(i=1,2, \ldots, n, E C B)$ as

$$
M_{i}=\left(\begin{array}{cccccccc}
Q_{i} & S_{1 i} & S_{2 i} & S_{3 i} & \ldots & S_{(n-1) i} & S_{n i} & S_{E C B i} \\
S_{1 i}^{\top} & R_{1 i} & P_{11[i]} & P_{12[i]} & \ldots & P_{1(n-2)[i]} & P_{1(n-1)[i]} & P_{1 n[i]} \\
S_{2 i}^{\top} & P_{11[i]}^{\top} & R_{2 i} & P_{22[i]} & \ldots & P_{2(n-2)[i]} & P_{2(n-1)[i]} & P_{2 n[i]} \\
S_{3 i}^{\top} & P_{12[i]}^{\top} & P_{22[i]}^{\top} & R_{3 i} & \ldots & P_{3(n-2)[i]} & P_{3(n-1)[i]} & P_{3 n[i]} \\
\ldots & \ldots & \ldots & \ldots & \ldots & \ldots & \ldots & \ldots \\
S_{(n-1) i}^{\top} & P_{1(n-2)[i]}^{\top} & P_{2(n-2)[i]}^{\top} & & \ldots & R_{(n-1) i} & P_{(n-1)(n-1)[i]} & P_{(n-1) n[i]} \\
S_{n i}^{\top} & P_{1(n-1)[i]}^{\top} & P_{2(n-1)[i]}^{\top} & P_{3(n-1)[i]}^{\top} & \ldots & P_{(n-1)(n-1)[i]}^{\top} & R_{n i} & P_{n n[i]} \\
S_{E C B i}^{\top} & P_{1 n[i]}^{\top} & P_{2 n[i]}^{\top} & P_{3 n[i]}^{\top} & \ldots & P_{(n-1) n[i]}^{\top} & P_{n n[i]}^{\top} & R_{E C B i}
\end{array}\right)
$$

for $i \in\{\bar{N} \cup E C B\}$, where $Q_{i} \in \mathbb{R}^{n \times n}, S_{i j} \in \mathbb{R}^{n \times 1}$, while $R_{i j}$ for $j \in\{\bar{N} \cup E C B\}$ and the other coefficients are scalars.

2. Compute the following matrices:

$$
\begin{aligned}
& G:=\left(\begin{array}{ccccc}
R_{11} & P_{11[1]} & \ldots & P_{1(n-1)[1]} & P_{1 n[1]} \\
P_{n n[2]}^{\top} & R_{22} & \ldots & P_{2(n-1)[i]} & P_{2 n[i]} \\
\ldots & \ldots & \ldots & \ldots & \ldots \\
P_{2 n[n]}^{\top} & P_{2(n-1)[n]}^{\top} & \ldots & R_{n n} & P_{n n[n]} \\
P_{1 n[E C B]}^{\top} & P_{1(n-1)[E C B]}^{\top} & \ldots & P_{n n[E C B]}^{\top} & R_{E C B E C B}
\end{array}\right) \\
& H_{1}:=\left(\begin{array}{cccccc}
-A & 0 & 0 & 0 & \ldots & 0 \\
Q_{1} & A^{\top} & 0 & 0 & \ldots & 0 \\
Q_{2} & 0 & A^{\top} & 0 & \ldots & 0 \\
\ldots & \ldots & \ldots & \ldots & \ldots & \ldots \\
Q_{n} & 0 & 0 & A^{\top} & \ldots & 0 \\
Q_{E C B} & 0 & 0 & 0 & \ldots & A^{\top}
\end{array}\right) \\
& H_{2}:=\left(\begin{array}{ccccc}
B_{1} & B_{2} & \ldots & B_{n} & M \\
-S_{11} & -S_{21} & \ldots & -S_{n 1} & -S_{E C B 1} \\
-S_{12} & -S_{22} & \ldots & -S_{n 2} & -S_{E C B 2} \\
\ldots & \ldots & \ldots & \ldots & \ldots \\
-S_{1 n} & -S_{2 n} & \ldots & -S_{n n} & -S_{E C B n} \\
-S_{1 E C B} & -S_{2 E C B} & \ldots & -S_{n E C B} & -S_{E C B E C B}
\end{array}\right) \\
& H_{3}:=\left(\begin{array}{cccccc}
S_{11}^{\top} & B_{1}^{\top} & 0 & \ldots & 0 & 0 \\
S_{22}^{\top} & 0 & B_{2}^{\top} & \ldots & 0 & 0 \\
\ldots & \ldots & \ldots & \ldots & \ldots & \ldots \\
S_{n n}^{\top} & 0 & 0 & \ldots & B_{n}^{\top} & 0 \\
S_{E C B E C B}^{\top} & 0 & 0 & \ldots & O & M^{\top}
\end{array}\right)
\end{aligned}
$$


where $B_{i}$ is the $i$ th column of matrix $B$. Then, we can define the following matrix:

$$
H:=H_{1}+H_{2} G^{-1} H_{3}
$$

4. After computing the eigenstructure of $H$, take $n$ positive eigenvalues and the corresponding eigenvectors $v_{i}$ to write the following expression: ${ }^{27}$

$$
\left(\begin{array}{c}
X \\
Y_{1} \\
Y_{2} \\
\ldots \\
Y_{n} \\
Y_{E C B}
\end{array}\right):=\left(\begin{array}{llll}
v_{1} & v_{2} & \ldots & v_{n}
\end{array}\right):=V \in \mathbb{R}^{n(n+2) \times n}
$$

from which we can derive the optimal controls:

$$
\left(\begin{array}{c}
f_{1}(t) \\
f_{2}(t) \\
\ldots \\
f_{n}(t) \\
i_{E C B}(t)
\end{array}\right)=-G^{-1}\left(\begin{array}{c}
S_{11}^{\top}+B_{1}^{\top} K_{1} \\
S_{22}^{\top}+B_{2}^{\top} K_{2} \\
\cdots \\
S_{n n}^{\top}+B_{n}^{\top} K_{n} \\
S_{E C B E C B}^{\top}+M_{E C B}^{\top} K_{n+1}
\end{array}\right) p=: F p
$$

where $K_{i}:=Y_{i} X^{-1}$ for $i \in\{\bar{N} \cup E C B\}$.

5. Rewrite the policymakers' cost functions ${ }^{28}$ and the dynamics of the model as $J_{i}(t)=\frac{1}{2} \int_{0}^{\infty} p^{\top}\left[\left(I, F^{\top}\right) M_{i}\left(\begin{array}{c}I \\ F\end{array}\right)\right] p(t) d t$ and $\dot{p}(t)=(A+(B N) F) p(t)=: A_{C L} p(t)$, respectively. The problem is then solved by considering:

$$
J_{i}=p_{0}^{\top} \tilde{L}_{i} p_{0}
$$

where $\tilde{L}_{i}$ solves the following Lyapunov equation (for $i \in\{\bar{N} \cup E C B\}$ ):

$$
A_{C L}^{\top} \tilde{L}_{i}+\tilde{L}_{i} A_{C L}+\frac{1}{2}\left(I, F^{\top}\right) M_{i}\left(\begin{array}{c}
I \\
F
\end{array}\right)=0
$$

Cooperative solutions are achieved by using the same algorithm but considering joint optimal losses minimization ${ }^{29}$.

\footnotetext{
${ }^{27}$ If matrix $H$ has more than $n$ positive eigenvalues multiple equilibria arise, whereas if this matrix has less than $n$ positive eigenvalues no equilibrium exists (for more details see Engwerda (1998)).

${ }^{28}$ For reasons of convenience, we assume that $t_{0}=0$ and $\theta$ is equal to zero. Assuming $\theta$ different from zero, the model could easily be solved following the procedure used in this paper after a simple transformation of variables, i.e. transforming $x(t)$ into $e^{-\frac{1}{2} \theta t} x(t)$ and substituting $A$ by $A-\frac{1}{2} \theta I$ where $I \in \mathbb{R}^{n \times n}$ is a diagonal matrix with ones on the main diagonal (see Engwerda et al. (1999), p.263, for further details).

${ }^{29}$ For more details see e.g.: van Aarle et al. (2002b) or Engwerda et al. (2002, Appendix B).
} 


\section{Appendix (cont.)}

\section{Two algorithms to calculate coalitional equilibria}

Two algorithms are presented which give two different ways how coalitions might be formed. The first one is based on Bloch's (1996) ideas and describes a sequential process how coalitions might be formed. The second is based on the idea of farsightedness and describes which coalitions can be ruled out in this situation. It does not determine what will happen but what possibly can happen. The sequential coalition formation process (computing the SNE) and the farsighted process (computing the FCE) should mimic the various cases.

\section{The sequential coalition formation process}

\section{a) Sequential Negotiation Equilibrium}

The SNE is a structured negotiation process, where players due to limited information (it is assumed that a player knows only her optimal losses) do not act strategically. Instead they decide to adopt the following procedure of finding an equilibrium:

1. Fix a rule of order for the players, which is used to determine the order of moves in the sequential game of coalition formation.

2. The first player starts the game according to the rule of order by considering the question whether it is rational for her to propose a coalition. To that end she considers the worst possible outcome that can occur if she does not form a coalition, i.e. ${ }^{30}$ :

$$
J_{1}^{r}:=\max _{(\{1\},\{.\})} J_{1}(.) .
$$

If $J_{1}^{r}$ is smaller than the cost she infers by forming whatever coalition, player 1 will propose no coalition and leaves the game. That is, the game continues with step 2 . with player 1 playing non-cooperatively and player 2 starting the game.

If there is at least one coalition form where the cost of player 1 is lower than $J_{1}^{r}$ we assume ${ }^{31}$ that player 1 will propose a coalition according to the following rules:

i) Select that coalition where her cost is as small as possible.

ii) If there is more than one coalition satisfying i), choose that coalition containing

\footnotetext{
${ }^{30}$ Notation: $(\{1\}\{\}$.$) denotes the case in which player 1$ plays non-coperatively, whereas other players may form any coalitions (but may also play non-cooperatively).

${ }^{31}$ Note that we assume here that player 1 is risk averse, i.e. it might happen that e.g. in the noncooperative case her cost is lower than the minimal cost she can incur by forming any coalition. However, since she is not able to enforce the non-cooperative solution, we choose to select this definition of rationality.
} 
the most important players.

iii) If there is more than one coalition satisfying ii), select that coalition which contains the highest number of players.

Rules ii) and iii) say that e.g. the coalition $\{1,2,3\}$ is preferred above the coalitions $\{1,2\}$ and $\{1,2,4\}$.

Next proceed with step 3.

3. Verify whether all players in the coalition agree on this coalition according to the rule of order. That is: player $i$ agrees on this coalition if her cost in this coalition is smaller or equal than both the cost she incurs by joining any other feasible coalition and the worst possible outcome if she does not join any feasible coalition. The set of feasible coalitions is determined by the history of the game. That is, the set of feasible coalitions, $F C$, contains only those coalitions which are still realizable given the history of the game. More formally, verify whether:

$$
J_{i}(\text { coalition }) \leq \min \left\{\min _{(\{i, . .\},\{. .\}) \in F C} J_{i}(.), \max _{(\{i\},\{. .\}) \in F C} J_{i}(.)\right\} .
$$

holds for all players in the foreseen coalition.

4. If all players agree on the coalition, the coalition is formed and the players leave the game. The coalition process repeats with the remaining players from step 2 . on.

If not all players agree, the first player who disagrees may come up with a coalition proposal if she did not have this opportunity for this set of feasible coalitions before. In that case the coalition process repeats from step 2. on. Otherwise, a cycle has occurred, and the coalition formation process would repeat itself ad infinitum. We assume that in that case all players that are still involved in the formation process all play non-cooperatively.

\section{Example (Table 2):}

1. Order: $1,2,3, \mathrm{ECB}$

2. Player 1 may propose: $J_{1}^{r}=\max \{24.7620 ; 24.7487\}=24.7620$.

Player 1 proposes the full coalition $C$ as: $J_{C 1}=\min \{24.6479,24.7708,24.7755\}=24.6479<J_{1}^{r}=24.7620$.

3 . Reaction of other players to the proposal of the Player 1 :

Player 2 accepts full coalition $C$, as: $J_{C 2}=\min \{\min \{24.6479,24.7708,24.7755\}, \max \{24.7620 ; 24.7487\}\}=24.6479$.

Player 3 accepts full coalition $C$, as: $J_{C 3}=\min \{\min \{24.6479,24.7708,24.7755\}, \max \{24.7620 ; 24.7487\}\}=24.6479$.

Player 4 accepts full coalition $C$, as: 
$J_{E C B}=\min \{\min \{48.0783\}, \max \{54.1579,54.5365,54.5463\}\}=48.0783$.

Therefore, $S N E=C$.

b) Sequential Negotiation Game Equilibrium

Figure A1

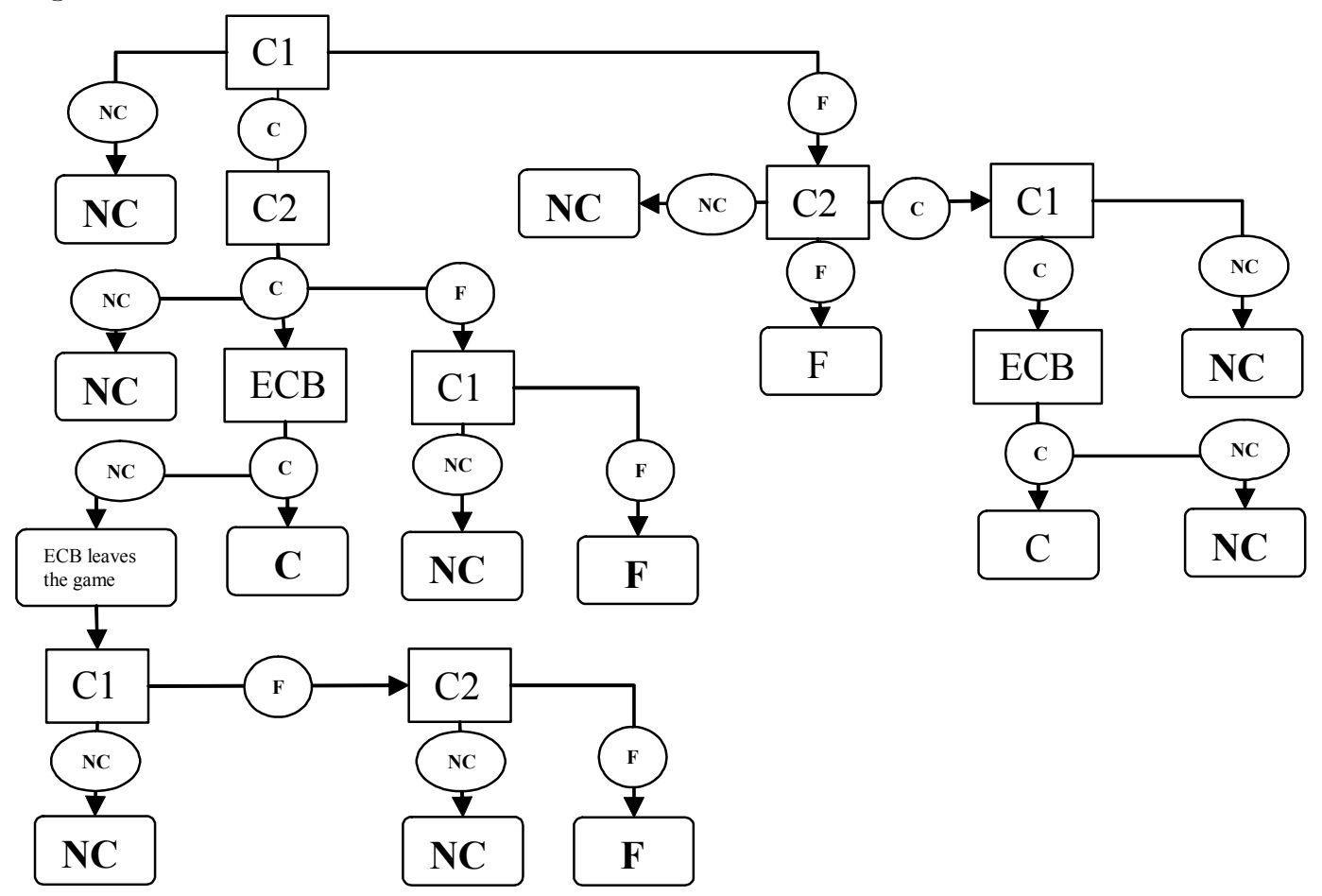

where:

\begin{tabular}{l}
\hline \\
\hline
\end{tabular} - stands for decision node of the $i$-th player, i $=\mathrm{C} 1, \mathrm{C} 2, \mathrm{ECB}$;

(i) - stands for a proposal made, where $j=\mathrm{NC}, \mathrm{C}, \mathrm{F}$; and

$t$ - stands for terminal node, $t=\mathrm{NC}, \mathrm{C}, \mathrm{F}$.

In the SNGE we assume that players agree to follow the same rules of coalition formation but differently from the SNE they have perfect information about each others' optimal losses in different coalition structures. Therefore, they play a finite strategic game, which can be presented in the extensive form and solved by backward induction. Unfortunately the game tree for the case utilized in this paper of four players and six possible outcomes of coalition formation has about 4240 decision nodes (depending on a notation assumed). Therefore we present below a very simple example for three players and three feasible coalitional outcomes: 


\begin{tabular}{cccc}
\multicolumn{5}{c}{ Table A1: Example of SNGE } \\
\hline \multirow{4}{*}{ Country 1 } & 5 & $C$ & $F$ \\
Country 2 & 4 & 3 & 4 \\
ECB & 3 & 2 & 3 \\
\hline
\end{tabular}

The game tree for the order of players $[\mathrm{C} 1, \mathrm{C} 2, \mathrm{ECB}]$ is presented in Figure A1. Solving the game with backward induction with the assumption presented in the SNE algorithm above leads to the outcome $F$.

\section{The farsighted coalition process}

1. Make a preference list for each of the individual players, i.e. for each player determine which coalition yields the lowest cost, the one-but lowest cost etc.

2. Determine for each player $i$ the minimum cost it can enforce by playing noncooperatively, i.e. determine for each $i$

$$
J_{i}^{r}:=\max _{(\{i\},\{. .\})} J_{i}(.)
$$

3. Determine for each player $i$ all coalitions for which $J_{i}(.) \leq J_{i}^{r}$. Denote this set of feasible coalitions for each player $i$ by $F C(i)$.

4. Determine all coalitions which are in the intersection of all sets of feasible coalitions. Call this set the Rational Feasible Coalitions set $(R F C)$.

5. Drop within the set $R F C$ those coalitions which are Pareto dominated by another coalition. That is, if e.g. both coalitions $F$ and $C$ belong to $R F C$ but $C$ is preferred by every player above $F$, the coalition $F$ is dropped from the set $R F C$.

6. Look for coalitions within this set that satisfy some additional properties as internal and external stability, or exogenous factors that support certain equilibria.

\section{Example (Table 2):}

\section{Table 4}

1. Preference list:

Player 1: $C \succeq(2,3) \succeq N C \succeq F \succeq(1,2)=(1,3)$

Player 2: $C \succeq(1,3) \succeq N C \succeq F \succeq(1,2)=(2,3)$

Player 3: $C \succeq(1,2) \succeq N C \succeq F \succeq(1,2)=(1,3)$

ECB: $C \succeq N C \succeq(1,2)=(2,3)=(1,3) \succeq F$

2. Maximum cost of non-cooperative playing:

$J_{1}^{r}=J_{2}^{r}=J_{3}^{r}=\max \{24.7620,24.7487\}=24.7620 ;$

$J_{4}^{r}=\max \{54.1579,48.9783,54.5365,54.3463\}=54.5365$. 
3. $F C$ for each player:

$F C(1)=\{N C, C,(2,3)\}$

$F C(2)=\{N C, C,(1,3)\}$

$F C(3)=\{N C, C,(1,2)\}$

$F C(4)=\{N C, C, F,(1,2),(1,3),(2,3)\}$

5. $R F C=\{N C, C\}$

6. $N C$ is Pareto-dominated by C. Hence, $\mathrm{FCE}=C, F$. 


\section{References}

Aarle, B. van, J. Engwerda and J. Plasmans (2002a), "Monetary and fiscal policy interaction in the EMU: A dynamic game approach", Annals of Operations Research, vol. 109, pp. 229-264.

Aarle, B. van, G. Di Bartolomeo, J. Engwerda and J. Plasmans (2002b), "Coalitions and dynamic interactions between fiscal and monetary authorities in the EMU", Ifo Studien, vol. 48, No. 2, pp. 207-229.

Angeloni, I., A. Kashyap, B. Mojon and D. Terlizzese (2002), "Monetary transmission in the Euro-area: Where do we stand?", ECB Working Paper no.114.

d'Aspremont, C.A., A. Jacquemin, J.J. Gabszewicz and J. Weymark (1983) "On the stability of collusive price leadership", Canadian Journal of Economics, vol. 16, pp. $17-25$.

Beetsma, R.M.W.J., X. Debrun and F. Klaassen (2001), "Is fiscal policy coordination in EMU desirable?", CESIfo Working Paper No. 599, Center for Economic Studies and Ifo Institute for Economic Research, Munich.

Bloch, F. (1996), "Sequential formation of coalitions in games with externalities and fixed payoff division", Games and Economic Behavior, vol. 14, pp. 90-123.

Buti, M. and A. Sapir (Eds.) (1998), Economic Policy in EMU: A Study by the European Commission Services, Oxford University Press, Oxford.

Carraro C. and D. Siniscalco (1998), "International environmental agreements: Incentives and political economy", European Economic Review, vol. 42, pp. 561-572.

CESifo (2002), Report on the European Economy 2002, Center for Economic Studies and Ifo Institute for Economic Research, Munich.

Chwe, M.S. (1994), "Farsighted coalitional stability", Journal of Economic Theory, vol. 54, pp. 299-325.

Clarida, R., J. Galí and M. Gertler (1999), "The Science of Monetary Policy: A New Keynesian Perspective", Journal of Economic Literature, vol. 37, pp. 1661-1707.

Di Bartolomeo, G., J.C. Engwerda, J.E.J. Plasmans and B. van Aarle (2004), "Staying together or breaking apart: Policy-makers' endogenous coalitions formation in the European Economic and Monetary Union", Computers and Operations Research, forthcoming.

DiNardo, J. and M.P. Moore (1999), "The Phillips Curve is Back? Using Panel Data to Analyze the Relationship Between Unemployment and Inflation in an Open Economy", National Bureau of Economic Research Working Paper No. 7328. 
ECB (1999), "The stability-oriented monetary policy in the Eurosystem", Monthly Bulletin (January), Frankfurt, ECB.

Ecchia, G. and M. Mariotti (1998), "Coalition formation in international environmental agreements and the role of institutions", European Economic Review, vol. 42, pp. 573-582.

Engwerda, J. (1998), "Computational aspects of the open-loop Nash equilibrium in linear quadratic games", Journal of Economic Dynamics and Control, vol. 22, pp. 1487-1506.

Engwerda, J., B. van Aarle and J. Plasmans (1999), "The (in)finite horizon open-loop Nash LQ game: An application to the EMU", Annals of Operations Research, vol. 88, pp. 251-273.

Engwerda, J., B. van Aarle and J. Plasmans (2002), "Cooperative and non-cooperative fiscal stabilisation policies in the EMU", Journal of Economic Dynamics and Control, vol. 26, pp. 451-481.

European Commission (2001), "Public finances in EMU - 2001", European Economy Reports and Studies, No. 3.

Hooper, P., K. Johnson and J. Marquez (1998), "Trade elasticities for G-7 countries", Board of Governors of the Federal Reserve System International Finance Discussion Paper no. 609.

Hughes Hallett A. and N. Viegi (2003), "On the need for Inter-institutional Coordination in EMU: a re-evaluation of the theory of optimal currency areas", in F. Breuss, G. Fink and S. Griller (eds.), Institutional, Legal and Economic Aspects of the EMU, Springer, New York.

Laxton, D., P. Isard, H. Faruqee, E. Prasad and B. Turtleboom (1998), "MULTIMOD Mark III - The Core Dynamic and Steady-State Models", IMF Occasional Paper no. 164.

Mariotti, M. (1998), "A model of agreements in a strategic form games", Journal of Economic Theory, vol. 73, pp. 128-139.

Monteforte, L. and S. Siviero, "Aggreate vs. Disaggregate Euro-Area Macro-Modelling", mimeo, Bank of Italy.

Monfort, A., J.P. Renne, R. Ruffer and G. Vitale (2002), "Is Economic Activity in the G7 Synchronised? Common Schock vs. Spillovers Effects", mimeo.

Neck R., G. Haber and W.J. McKibbin (2002), "Global Implications of Monetary and Fiscal Policy Rules in the EMU", Open Economies Review 13 (2002), 363-379.

Onorante, L. (2002), "The interaction of fiscal policies in the Euro area: how much pressure on the $\mathrm{ECB}_{i}$, Cambridge, Cambridge University Press, forthcoming. 
Plasmans, J., G. Di Bartolomeo, B.Merlevede, and B. van Aarle (2004), "Monetary policy regimes with hybrid output gaps and inflation rates with an application to EU-accession countries", in S. Kesenne and C. Reyns (eds.), Kwantitatief bekeken, Liber Amicorum Prof. dr. Robert Van Straelen, pp. 95-136, Garant, AntwerpenApeldoorn.

Ray, D. and R. Vohra (1999). "A theory of endogenous coalition structures", Games and Economic Behavior, vol. 26, pp. 286-336.

Razin, A. and C.W. Yuen (2001), “The 'New Keynesian' Phillips curve: Closed economy vs. open economies", National Bureau of Economic Research Working Paper No. 8313 .

Smets, F. (2000), "What horizon for price stability", ECB Working Paper no. 24.

Uhlig, H.(2002), "One money, but many fiscal policies in Europe: what are the consequences?", CentER Discussion Paper No. 32. 


\title{
CESifo Working Paper Series
}

\author{
(for full list see www.cesifo.de)
}

1313 Kurt Schmidheiny, Income Segregation and Local Progressive Taxation: Empirical Evidence from Switzerland, October 2004

1314 David S. Evans, Andrei Hagiu and Richard Schmalensee, A Survey of the Economic Role of Software Platforms in Computer-Based Industries, October 2004

1315 Frank Riedel and Elmar Wolfstetter, Immediate Demand Reduction in Simultaneous Ascending Bid Auctions, October 2004

1316 Patricia Crifo and Jean-Louis Rullière, Incentives and Anonymity Principle: Crowding Out Toward Users, October 2004

1317 Attila Ambrus and Rossella Argenziano, Network Markets and Consumers Coordination, October 2004

1318 Margarita Katsimi and Thomas Moutos, Monopoly, Inequality and Redistribution Via the Public Provision of Private Goods, October 2004

1319 Jens Josephson and Karl Wärneryd, Long-Run Selection and the Work Ethic, October 2004

1320 Jan K. Brueckner and Oleg Smirnov, Workings of the Melting Pot: Social Networks and the Evolution of Population Attributes, October 2004

1321 Thomas Fuchs and Ludger Wößmann, Computers and Student Learning: Bivariate and Multivariate Evidence on the Availability and Use of Computers at Home and at School, November 2004

1322 Alberto Bisin, Piero Gottardi and Adriano A. Rampini, Managerial Hedging and Portfolio Monitoring, November 2004

1323 Cecilia García-Peñalosa and Jean-François Wen, Redistribution and Occupational Choice in a Schumpeterian Growth Model, November 2004

1324 William Martin and Robert Rowthorn, Will Stability Last?, November 2004

1325 Jianpei Li and Elmar Wolfstetter, Partnership Dissolution, Complementarity, and Investment Incentives, November 2004

1326 Hans Fehr, Sabine Jokisch and Laurence J. Kotlikoff, Fertility, Mortality, and the Developed World's Demographic Transition, November 2004

1327 Adam Elbourne and Jakob de Haan, Asymmetric Monetary Transmission in EMU: The Robustness of VAR Conclusions and Cecchetti's Legal Family Theory, November 2004 
1328 Karel-Jan Alsem, Steven Brakman, Lex Hoogduin and Gerard Kuper, The Impact of Newspapers on Consumer Confidence: Does Spin Bias Exist?, November 2004

1329 Chiona Balfoussia and Mike Wickens, Macroeconomic Sources of Risk in the Term Structure, November 2004

1330 Ludger Wößmann, The Effect Heterogeneity of Central Exams: Evidence from TIMSS, TIMSS-Repeat and PISA, November 2004

1331 M. Hashem Pesaran, Estimation and Inference in Large Heterogeneous Panels with a Multifactor Error Structure, November 2004

1332 Maarten C. W. Janssen, José Luis Moraga-González and Matthijs R. Wildenbeest, A Note on Costly Sequential Search and Oligopoly Pricing, November 2004

1333 Martin Peitz and Patrick Waelbroeck, An Economist's Guide to Digital Music, November 2004

1335 Lutz Hendricks, Why Does Educational Attainment Differ Across U.S. States?, November 2004

1336 Jay Pil Choi, Antitrust Analysis of Tying Arrangements, November 2004

1337 Rafael Lalive, Jan C. van Ours and Josef Zweimueller, How Changes in Financial Incentives Affect the Duration of Unemployment, November 2004

1338 Robert Woods, Fiscal Stabilisation and EMU, November 2004

1339 Rainald Borck and Matthias Wrede, Political Economy of Commuting Subsidies, November 2004

1340 Marcel Gérard, Combining Dutch Presumptive Capital Income Tax and US Qualified Intermediaries to Set Forth a New System of International Savings Taxation, November 2004

1341 Bruno S. Frey, Simon Luechinger and Alois Stutzer, Calculating Tragedy: Assessing the Costs of Terrorism, November 2004

1342 Johannes Becker and Clemens Fuest, A Backward Looking Measure of the Effective Marginal Tax Burden on Investment, November 2004

1343 Heikki Kauppi, Erkki Koskela and Rune Stenbacka, Equilibrium Unemployment and Capital Intensity Under Product and Labor Market Imperfections, November 2004

1344 Helge Berger and Till Müller, How Should Large and Small Countries Be Represented in a Currency Union?, November 2004

1345 Bruno Jullien, Two-Sided Markets and Electronic Intermediaries, November 2004

1346 Wolfgang Eggert and Martin Kolmar, Contests with Size Effects, December 2004 
1347 Stefan Napel and Mika Widgrén, The Inter-Institutional Distribution of Power in EU Codecision, December 2004

1348 Yin-Wong Cheung and Ulf G. Erlandsson, Exchange Rates and Markov Switching Dynamics, December 2004

1349 Hartmut Egger and Peter Egger, Outsourcing and Trade in a Spatial World, December 2004

1350 Paul Belleflamme and Pierre M. Picard, Piracy and Competition, December 2004

1351 Jon Strand, Public-Good Valuation and Intrafamily Allocation, December 2004

1352 Michael Berlemann, Marcus Dittrich and Gunther Markwardt, The Value of NonBinding Announcements in Public Goods Experiments: Some Theory and Experimental Evidence, December 2004

1353 Camille Cornand and Frank Heinemann, Optimal Degree of Public Information Dissemination, December 2004

1354 Matteo Governatori and Sylvester Eijffinger, Fiscal and Monetary Interaction: The Role of Asymmetries of the Stability and Growth Pact in EMU, December 2004

1355 Fred Ramb and Alfons J. Weichenrieder, Taxes and the Financial Structure of German Inward FDI, December 2004

1356 José Luis Moraga-González and Jean-Marie Viaene, Dumping in Developing and Transition Economies, December 2004

1357 Peter Friedrich, Anita Kaltschütz and Chang Woon Nam, Significance and Determination of Fees for Municipal Finance, December 2004

1358 M. Hashem Pesaran and Paolo Zaffaroni, Model Averaging and Value-at-Risk Based Evaluation of Large Multi Asset Volatility Models for Risk Management, December 2004

1359 Fwu-Ranq Chang, Optimal Growth and Impatience: A Phase Diagram Analysis, December 2004

1360 Elise S. Brezis and François Crouzet, The Role of Higher Education Institutions: Recruitment of Elites and Economic Growth, December 2004

1361 B. Gabriela Mundaca and Jon Strand, A Risk Allocation Approach to Optimal Exchange Rate Policy, December 2004

1362 Christa Hainz, Quality of Institutions, Credit Markets and Bankruptcy, December 2004

1363 Jerome L. Stein, Optimal Debt and Equilibrium Exchange Rates in a Stochastic Environment: an Overview, December 2004 
1364 Frank Heinemann, Rosemarie Nagel and Peter Ockenfels, Measuring Strategic Uncertainty in Coordination Games, December 2004

1365 José Luis Moraga-González and Jean-Marie Viaene, Anti-Dumping, Intra-Industry Trade and Quality Reversals, December 2004

1366 Harry Grubert, Tax Credits, Source Rules, Trade and Electronic Commerce: Behavioral Margins and the Design of International Tax Systems, December 2004

1367 Hans-Werner Sinn, EU Enlargement, Migration and the New Constitution, December 2004

1368 Josef Falkinger, Noncooperative Support of Public Norm Enforcement in Large Societies, December 2004

1369 Panu Poutvaara, Public Education in an Integrated Europe: Studying to Migrate and Teaching to Stay?, December 2004

1370 András Simonovits, Designing Benefit Rules for Flexible Retirement with or without Redistribution, December 2004

1371 Antonis Adam, Macroeconomic Effects of Social Security Privatization in a Small Unionized Economy, December 2004

1372 Andrew Hughes Hallett, Post-Thatcher Fiscal Strategies in the U.K.: An Interpretation, December 2004

1373 Hendrik Hakenes and Martin Peitz, Umbrella Branding and the Provision of Quality, December 2004

1374 Sascha O. Becker, Karolina Ekholm, Robert Jäckle and Marc-Andreas Mündler, Location Choice and Employment Decisions: A Comparison of German and Swedish Multinationals, January 2005

1375 Christian Gollier, The Consumption-Based Determinants of the Term Structure of Discount Rates, January 2005

1376 Giovanni Di Bartolomeo, Jacob Engwerda, Joseph Plasmans, Bas van Aarle and Tomasz Michalak, Macroeconomic Stabilization Policies in the EMU: Spillovers, Asymmetries, and Institutions, January 2005 